\title{
Foam Cells as Therapeutic Targets in Atherosclerosis with a Focus on the Regulatory Roles of Non-Coding RNAs
}

\author{
Amin Javadifar ${ }^{1}$, Sahar Rastgoo ${ }^{1}$, Maciej Banach ${ }^{2,3, * \mathbb{D}}$, Tannaz Jamialahmadi ${ }^{4,5}$, Thomas P. Johnston ${ }^{6}$ \\ and Amirhossein Sahebkar $7,8,9,10, *$
}

1 Department of Allergy and Immunology, Mashhad University of Medical Sciences,

Mashhad 9177948564, Iran; javadifarA971@mums.ac.ir (A.J.); rastgous971@mums.ac.ir (S.R.)

2 Department of Hypertension, Chair of Nephrology and Hypertension, Medical University of Lodz, 93338 Lodz, Poland

3 Polish Mother's Memorial Hospital Research Institute (PMMHRI), 93338 Lodz, Poland

4 Department of Food Science and Technology, Quchan Branch, Islamic Azad University, Quchan 9479176135, Iran; jamiat931@gmail.com

5 Department of Nutrition, Faculty of Medicine, Mashhad University of Medical Sciences, Mashhad 9177948564, Iran

6 Division of Pharmacology and Pharmaceutical Sciences, School of Pharmacy, University of Missouri-Kansas City, Kansas City, MO 64108-2718, USA; Johnstont@umkc.edu

7 Biotechnology Research Center, Pharmaceutical Technology Institute, Mashhad University of Medical Sciences, Mashhad 9177948564, Iran

8 Applied Biomedical Research Center, Mashhad University of Medical Sciences, Mashhad 9177948564, Iran

9 School of Pharmacy, Mashhad University of Medical Sciences, Mashhad 9177948954, Iran

10 Department of Medical Biotechnology and Nanotechnology, School of Medicine, Mashhad University of Medical Sciences, Mashhad 9177948564, Iran

Citation: Javadifar, A.; Rastgoo, S.; Banach, M.; Jamialahmadi, T.; Johnston, T.P.; Sahebkar, A. Foam Cells as Therapeutic Targets in Atherosclerosis with a Focus on the Regulatory Roles of Non-Coding RNAs. Int. J. Mol. Sci. 2021, 22, 2529. https://doi.org/10.3390/ijms22052529

Academic Editor: Noemí Rotllan

Received: 14 January 2021

Accepted: 24 February 2021

Published: 3 March 2021

Publisher's Note: MDPI stays neutral with regard to jurisdictional claims in published maps and institutional affiliations.

Copyright: (C) 2021 by the authors Licensee MDPI, Basel, Switzerland. This article is an open access article distributed under the terms and conditions of the Creative Commons Attribution (CC BY) license (https:// creativecommons.org/licenses/by/ $4.0 /)$.
* Correspondence: maciejbanach@aol.co.uk (M.B.); sahebkara@mums.ac.ir or amir_saheb2000@yahoo.com (A.S.); Tel.: +98-5118002288 (M.B. \& A.S.); Fax: +98-5118002287 (M.B. \& A.S.)

\begin{abstract}
Atherosclerosis is a major cause of human cardiovascular disease, which is the leading cause of mortality around the world. Various physiological and pathological processes are involved, including chronic inflammation, dysregulation of lipid metabolism, development of an environment characterized by oxidative stress and improper immune responses. Accordingly, the expansion of novel targets for the treatment of atherosclerosis is necessary. In this study, we focus on the role of foam cells in the development of atherosclerosis. The specific therapeutic goals associated with each stage in the formation of foam cells and the development of atherosclerosis will be considered. Processing and metabolism of cholesterol in the macrophage is one of the main steps in foam cell formation. Cholesterol processing involves lipid uptake, cholesterol esterification and cholesterol efflux, which ultimately leads to cholesterol equilibrium in the macrophage. Recently, many preclinical studies have appeared concerning the role of non-encoding RNAs in the formation of atherosclerotic lesions. Non-encoding RNAs, especially microRNAs, are considered regulators of lipid metabolism by affecting the expression of genes involved in the uptake (e.g., CD36 and LOX1) esterification (ACAT1) and efflux (ABCA1, ABCG1) of cholesterol. They are also able to regulate inflammatory pathways, produce cytokines and mediate foam cell apoptosis. We have reviewed important preclinical evidence of their therapeutic targeting in atherosclerosis, with a special focus on foam cell formation.
\end{abstract}

Keywords: atherosclerosis; lipid metabolism; noncoding RNAs; foam cell formation

\section{Introduction}

Atherosclerosis is a chronic, progressive immuno-inflammatory disease that affects blood vessels and can result in the development of atherosclerotic plaques. These plaques have the potential to rupture and lead to cardiovascular disease, especially myocardial infarction (MI) or stroke, which represent two of the leading causes of death worldwide [1]. 
Since foam cells are a central player in the underlying pathology of atherosclerosis, reducing the formation of foam cells, or inducing their removal, might represent an effective therapeutic strategy. Recently, several groups reported that targeting foam cells could effectively ameliorate atherosclerosis, which are described in this review. Current studies have suggested that non-coding RNAs are involved in the pathophysiology and progression of atherosclerosis and are good diagnostic and prognostic biomarkers, as well as therapeutic targets [1]. In this review, we discuss non-coding RNAs as therapeutic targets in the context of either enhancing or attenuating the formation of foam cells, which ultimately affects the metabolism and overall homeostasis of cholesterol.

\section{Pathophysiology of Atherosclerosis and the Key Role of Foam Cells}

The pathophysiology of atherosclerosis includes a complex network of different cellular processes and is associated with risk factors such as arterial hypertension, smoking, hyperglycemia and hypercholesterolemia [1]. One of the triggers of this disease is endothelial damage, which plays an important role in the formation of atherosclerotic plaques. Endothelial damage results in arteries experiencing a decrease in nitric oxide (NO) bioavailability and an increase in the production of reactive oxygen species (ROS) [2,3]. NO is an anti-atherogenic and vasoprotective factor essential for vascular health and is obtained by conversion of arginine to citrulline by endothelial nitric oxide synthase III (ENOS) [4]. Increased ROS also produce a state of oxidative stress that assists in the modification of LDL to its oxidized form (oxLDL). Platelets can also be activated by oxLDL and induce vascular inflammation [5,6]. Eventually, oxLDL, together with chronic low-grade inflammation resulting from endothelial injury, trigger an innate immune response and increase the recruitment of immune cells, especially monocytes and neutrophils, to the subendothelial space to participate in plaque formation. Recruitment of monocytes to the subendothelial space is mediated by the upregulation of cell adhesion molecules and chemokines (such as monocyte chemoattractant protein-1 (MCP-1)) via oxLDL signaling pathways $[7,8]$. The recruited monocytes then differentiate into macrophages mediated by colony-stimulating cytokines such as M-CSF and GM-CSF, both of which are enhanced through oxLDL-induced signaling pathways [9]. Macrophages also differentiate into inflammatory (M1) macrophages in the presence of the Th1 cytokine, or anti-inflammatory (M2) macrophages in the presence of the Th2 cytokine, in the subendothelial environment $[10,11]$. No M1 and M2 macrophages have been identified as specific precursors for foam cell formation, but several studies have shown that M2 macrophages are more susceptible to foam cell formation [12].

Another aspect of the pathophysiology of atherosclerosis is the dysregulation of cholesterol metabolism in the macrophage, which is the main cell responsible for atherosclerotic plaque [13]. Oxidized-LDL signaling pathways are involved in the downregulation of cholesterol efflux transporters. By increasing both the internalization of oxLDL and the accumulation of lipid droplets in the macrophage, foam cell formation gradually occurs, which initially leads to fatty streaks and ultimately, to primary atherosclerotic lesions. Foam cells play a central role in the pathogenesis of atherosclerosis. Specifically, the formation and accumulation of foam cells in the subendothelial space of a damaged artery is one of the early key steps responsible for the development of atherosclerosis [14,15]. MCP-1 and TNF- $\alpha$ represent two inflammatory mediators released during foam cell formation. MCP-1 increases vascular smooth muscle cell (VSMC) proliferation and leukocyte migration and TNF- $\alpha$ upregulates cell adhesion molecules (CAMs), which subsequently increases the recruitment of VSMCs and immune cells [16]. The proliferation of VSMCs inside the plaque temporarily stabilizes the lesion through collagen synthesis and other extracellular matrix (ECM) proteins, which function to maintain the integrity of the fibrous cap and inhibit cap rupture. Nevertheless, an increasing number of foam cells, which have pro-atherogenic properties, ultimately leads to plaque rupture and blood vessel occlusion due to the release of matrix-degrading enzymes $[17,18]$. Most plaque growth, or lesion progression, is a result of macrophage activity, although other immune cells (e.g., neutrophils), have also been 
shown to play an important role [19]. Eventually, the plaque ruptures and results in clinical manifestations recognized as MI and stroke [20].

\section{Foam Cells as Therapeutic Targets in Atherosclerosis}

Foam cell formation is one of the critical processes in the development and pathogenesis of atherosclerosis. As mentioned above, fatty streaks are the first detectable "yellow "lesion in the vessel wall that indicates foam cell formation and the development of atherosclerosis. Foam cells are involved in the formation of primary atherosclerotic plaques, their continued growth and ultimately, their rupture, which finally, leads to either MI or stroke $[5,12,14]$. The specific therapeutic goals associated with each stage in the formation of foam cells and the development of atherosclerosis will be considered below. Processing and metabolism of cholesterol in the macrophage is one of the major steps in foam cell formation. Cholesterol processing involves lipid uptake, cholesterol esterification and cholesterol efflux, which ultimately leads to cholesterol equilibrium in the macrophage. However, dysregulation and disruption of these processes results in foam cell formation [21]. During the development of atherosclerosis, chemoattractants (especially MCP-1) recruit monocytes to the subendothelial space of the damaged endothelium and they undergo differentiation to macrophages [22]. The macrophages express scavenger receptors SRA-1, SRA-2, CD36 and LOX1. Cellular uptake of oxLDL occurs by phagocytosis and pinocytosis via scavenger receptors, which preferentially incorporate oxLDL relative to its native (unmodified/unoxidized) form [23].

Numerous studies in mice have selectively targeted either chemoattractants or adhesion molecules involved in the recruitment of monocytes, or cytokines involved in the transmigration of monocytes. This has been accomplished by inactivating the genes encoding various molecules, such as M-CSF, CCL2, CXCR1 and CCR5, which has been shown to result in less and smaller atherosclerotic lesions in $\mathrm{ApoE}^{-/-}$mice [24-26]. Animal studies using LDLR $^{-/-}$mice have evaluated both the knockdown of VCAM-1 [27,28], or drug inhibition with a natural antioxidant AGI-1067, which showed successful and significant reductions in the development of atherosclerotic plaques in $\mathrm{LDLR}^{-/-}$mice [29]. SRA-1, 2, CD36 and LOX-1 are the primary scavenger receptors of macrophages that play a key role in lipid uptake and are controlled by several regulators such as MEKK-2, MAP kinases and STAT1 [23,30-32]. Numerous studies have targeted the role of these three major scavenger receptors in foam cell formation. For example, overexpression of LOX-1 in ApoE ${ }^{-/-}$mice accelerated the development of atherosclerosis, while LOX-1 ${ }^{-/-}$, $\mathrm{LDLR}^{-/-}$mice had smaller atherosclerotic lesions, which suggests a proatherogenic role for LOX-1 [33]. These receptors are multifunctional in nature and their expression is not limited to macrophages, because they are also expressed in aortic endothelial cells (ECs) and VSMCs. For these reasons, as well as the fact that different lipid uptake pathways exist, such as phagocytosis and pinocytosis, it is difficult to design studies that evaluate the therapeutic targeting of these receptors [34]. Additionally, an analysis of different studies indicates that there is still a debate between whether these receptors are pro-atherogenic, or anti-atherogenic $[35,36]$. Thus, we would suggest that further studies are needed to better understand the lipid uptake pathways and the true functional role of each of these receptors. In cholesterol esterification, ACAT-1 and neutral cholesterol ester hydrolase (NCEH) play a key role in catalyzing the esterification of cholesterol and removing cholesterol from macrophages, respectively $[37,38]$. ACAT- 1 is found ubiquitously in the endoplasmic reticulum of cells and is sensitive to the degree of membrane cholesterol enrichment, which is why it functions to maintain the cholesterol content of cell membranes at an optimal level by catalyzing the esterification of excess free cholesterol [39]. Studies have shown that ACAT-1 gene knockout in ApoE ${ }^{-/-}$and $\mathrm{LDLR}^{-/-}$mice resulted in no change in the development of atherosclerotic lesions and failed to inhibit foam cell formation [40]. However, pharmacological inhibition of ACAT-1 in macrophages has been shown to increase foam cell formation in mouse and rabbit models of atherosclerosis [41,42]. Moreover, animal studies evaluating the suppression of NCEH1 and hormone-sensitive lipase (LIPE), 
two important enzymes involved in the hydrolysis of cholesterol esters (CEs) back to free cholesterol (FC), have demonstrated a significant increase in intracellular CE accumulation when compared to control animals $[38,43]$. This would suggest that future studies should target all three enzymes (NCEH1, LIPE and ACAT-1) to intentionally modulate cholesterol turnover in macrophages.

Cholesterol efflux is one of the primary events in cholesterol metabolism and foam cell formation. The mechanism for cholesterol efflux is mainly attributable to ATP-binding cassette transporters ABCA1, ABCG1, as well as SR-B1, which function to maintain cholesterol and phospholipid homeostasis in the macrophage [44]. ABCA1 facilitates cholesterol and phospholipid efflux and leads to the formation of ApoA1, while ABCG1 mediates cholesterol efflux to form nascent high-density lipoprotein (HDL), which ultimately prevents the formation of foam cells. The expression of these transporters is predominantly dependent on the activation of PPAR and LXR $\alpha$ transcription factors [45]. Many studies have targeted these specific transporters. For example, in $\mathrm{LDLR}^{-/-}$mice treated with PPAR $\alpha$ and PPAR $\gamma$ agonists, the progression of atherosclerosis decreased due to the increased expression of ABCG1 and ABCA1 [46,47].

One of the limitations of targeting these transporters involved in cholesterol efflux pathways is that other pathways, such as passive diffusion, exist to transport cholesterol throughout the cell [48]. In studies that have been conducted, including genetic ablation of both ABCA1 and SR-B1 simultaneously in ABCA1 $\times$ SR-BI double knockout $(\mathrm{dKO})$ mice, macrophage RCT was markedly impaired and macrophage foam cell formation was increased in both lung and Peyer's patches of dKO mice. However, atherosclerotic lesions did not develop in these $\mathrm{dKO}$ mice, which was potentially due to the low levels of non-HDLC [49]. It should be noted, however, that hepatic overexpression of ABCA1 in LDLr-KO mice leads to enhanced aortic atherosclerotic lesions [49]. Therefore, knockdown studies on these three transporters could best be described as having yielded mixed results [50].

Cholesterol efflux inhibits the accumulation of excess lipids in the foam cell. Over time, the ability of the foam cell to manage the extra lipoproteins in the foam cell decreases, which leads to endoplasmic reticulum stress and the production of ROS and, in turn, triggers the apoptotic cascade. Additionally, uncontrolled lipoprotein uptake itself causes foam cell apoptosis [51,52].

Eventually, apoptosis of foam cells leads to the release of pro-inflammatory cytokines such as IL-1, IL-6, TNF-alpha and matrix metalloproteinases (MMPs); all, of which, may aggravate atherosclerosis by promoting an inflammatory state and the infiltration of immune cells [53].

The use of either pharmacological anti-inflammatory agents such as canakinumab, adalimumab and the TNF inhibitor etanercept, or agents that attenuate oxidative stress, may hold promise as a therapeutic intervention $[54,55]$.

Furthermore, trying to slow the death of foam cells might represent a therapeutic goal to prevent the development and worsening of atherosclerosis [56]. There are a number of strategies that could be employed to decelerate foam cell apoptosis. These include (1) targeting apoptotic pathways, such as the genetic inhibition of proapoptotic proteins such as BAX or Bcl-2 [57,58], (2) knockdown of apoptosis inhibitor of macrophages (AIM) [59], (3) targeting secondary necrosis pathways such as the clearance of apoptotic cells [60,61], (4) promoting efferocytosis of apoptotic macrophages by using LXR ligands or glucocorticoids $[62,63]$, or (5) by activating PPAR $\gamma$ pathways [64]. Another strategy to either control foam cell formation or increase the clearance of foam cells is statin therapy. Statins have been extensively investigated in patients with cardiovascular disease due to their numerous pleiotropic effects such as reducing oxidative stress, enhancing plaque stability and exerting anti-inflammatory effects [65-75]. Following foam cell formation, the foam cells take on a profibrotic phenotype. By releasing substances such as MMPs, they increase monocyte recruitment and degradation of extracellular matrix proteins such as collagen and fibronectin. This process leads to plaque instability and ultimately, plaque rupture [53,76]. For this reason, inhibition of MMPs may represent a treatment option in atherosclerosis. Many studies 
have targeted MMPs, in particular MMP8, because its increase in human carotid plaque has been associated with an unstable plaque phenotype [77]. Using $\mathrm{MMP}^{-/-} \mathrm{ApoE}^{-/-}$mice, it has been demonstrated that monocyte/leukocyte recruitment and macrophage lesions decrease. Moreover, either MMP-9 or MMP-12 deficiency in $\mathrm{ApoE}^{-/-}$mice has been shown to increase plaque instability [78-80]. Historically, monocyte-derived macrophages were considered the major source of plaque foam cells. However, other cells in the arterial wall such as ECs and VSMCs, as well as stem/progenitor cells (SPCs), show a foam cell phenotype in atherosclerotic plaques [81,82]. In fact, studies have shown that $50 \%$ of the foam cell population originates from VSMCs in human atherosclerotic lesions [83]. Therefore, this may suggest yet another strategy in the treatment of atherosclerosis; namely, targeting alternative cellular origins of foam cells [84-86]. Finally, one of the most important strategies for targeting foam cell formation is the use of miRNAs, which will be discussed in detail in this article.

The role and function of non-coding RNAs in foam cell formation and related processes (cholesterol efflux, cholesterol influx and cholesterol esterification) is depicted in Figure 1.

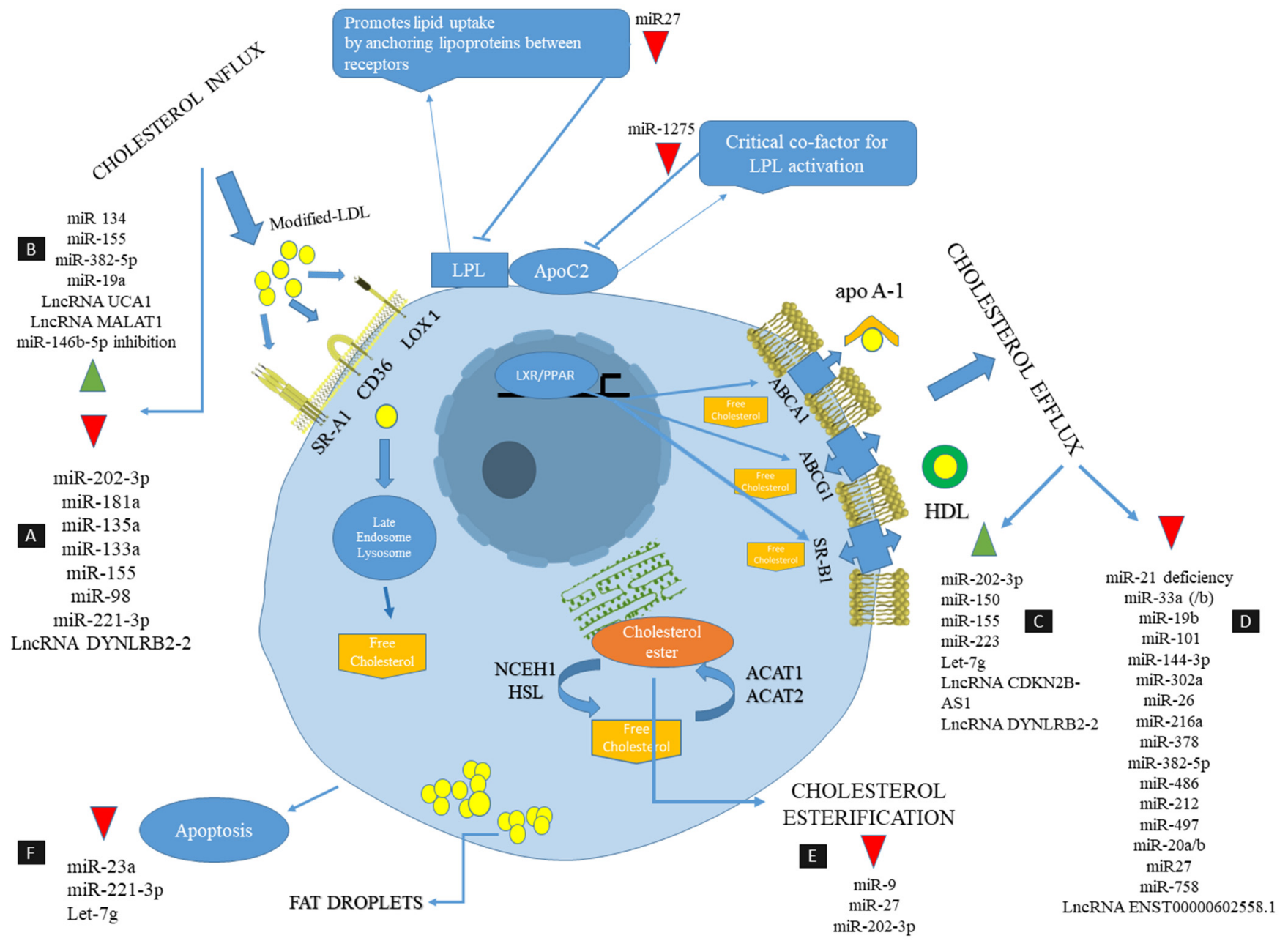

Figure 1. The mechanisms and molecules involved in cholesterol metabolism and homeostasis and the regulatory effects of Non-encoding RNAs are depicted in a foam cell. Cholesterol metabolism involves cholesterol influx, cholesterol esterification and cholesterol efflux, which ultimately leads to cholesterol homeostasis in the macrophage. Scavenger receptors SRA-1, CD36 and LOX1 are involved in oxLDL uptake. The gene expression of these receptors is downregulated in part A (see above); that is, non-encoding RNAs that have anti-atherosclerotic properties and are upregulated by part B ncRNAs, which are atherogenic and lead to lipid accumulation in macrophages. Cholesterol efflux is a pathway that transports excess free cholesterol from the cell, mainly via ABCA1, ABCG1, as well as SR-B1 transporters, leading to the formation of HDL and 
apoa1. The ncRNAs that reduce the formation of foam cells by increasing cholesterol efflux are specified in part $C$, as well as ncRNAs that lead to induction of the formation of foam cells by reducing cholesterol efflux, which are specified in part D. In cholesterol esterification, ACAT-1 and neutral cholesterol ester hydrolase (NCEH) play a key role in catalyzing the esterification of cholesterol and removing free cholesterol from foam cells, respectively. ACAT1 re-esterifies excess FC to promote the biosynthesis of CE that is stored in lipid droplets. In part E, microRNAs have been listed that reduce cholesterol esterification and increase the accumulation of free cholesterol, which ultimately promotes foam cell formation. Reducing foam cell apoptosis can stabilize atherosclerotic plaque and prevent the progression and worsening of atherosclerosis. ncRNAs that reduce foam cell apoptosis are shown in part F. $\nabla=$ decrease, $\Delta$ =increase.

\section{Non-Coding RNAs as Therapeutic Targets}

The development of modern genomic and transcriptomic techniques, mass spectrometry and bioinformatics has led to a greater understanding concerning the role of non-coding RNAs (ncRNAs) in the regulation of gene expression involved in cellular and pathogenic disease processes, especially in atherosclerosis and the role of foam cells. Many studies have been conducted to identify the capacity of ncRNAs to alter or improve the progression of atherosclerosis at the foam cell stage [87-90]. ncRNAs are molecules that do not translate into proteins and the size of ncRNAs correlates with their function. There are different classes of ncRNAs in biological processes. For example, those involved in the regulation of gene expression, such as miRNAs, piRNAs and lncRNAs; those involved in the maturation of RNAs (snRNAs, snoRNAs); and those involved in the synthesis of proteins (rRNAs, tRNAs). The ncRNAs are typically classified by size. Thus, ncRNAs that are less than 200 nucleotides in length are categorized as small ncRNAs (sncRNAs), while those that are over 200 nucleotides in length are considered long ncRNAs (lncRNAs) [91,92]. The length of microRNAs is between 20-24 nucleotides, which bind to the 3' untranslated region ( $3^{\prime}$ UTR) of the target mRNA and either prevent its translation, or cause it to degrade. Most miRs reduce gene expression post-transcription, although in some instances, miRs can increase gene expression by activating the translation of the target mRNA. MiRNAs are often transcribed by RNA polymerase II (its early version was termed pri-miRNA) [93-95]. Biogenesis of miRNA occurs via the canonical pathway involving Drosha and Dicer, as well as through different non-canonical pathways that are independent of Drosha and even Dicer. Single mRNAs can be involved in different biological processes and can also be targeted by different miRNAs. Therefore, miRNAs play a multifunctional role due to the fact that they can participate in separate biological processes, which represents one of the limitations of using miRNAs in basic research and clinical investigations [96,97]. LncRNAs have a size between $200 \mathrm{bp}$ to $100 \mathrm{~kb}$, which are capable of binding to DNA, protein and RNA at various levels, exerting cellular regulation such as chromatin remodeling, mRNA splicing, or mRNA translation and multi-protein complex assembly. Additionally, lncRNAs are transcribed by RNA polymerase II and most of them undergo alternative splicing, 5'-capping and polyadenylation processes [98,99].

LncRNAs may function in both the cis and trans configuration to regulate the expression of target genes. They are also able to use a set of different molecular mechanisms to accomplish this goal. For example, they may act as a scaffold for the recruitment of chromatin modifiers or transcription factors, act as decoys for the breakdown of proteins and function as miRNA sponges to activate or deactivate target genes [100,101]. Presently, lncRNAs are classified by their genomic localization and modes of action or function, including intronic lncRNAs and intergenic lncRNAs that originate from a different region of the gene. Most mature transcribed lncRNAs are thought to have little potential for protein-coding, because some of them contain small open reading frames and encode small functional peptides. Interestingly, lncRNAs have more functional diversity due to the fact that they have less conserved sequences and are under less selective pressure [98,102,103].

In pathological conditions, therapeutic strategies involving miRNAs primarily use miRNA inhibition to reduce the expression of miRNAs whose expression has increased and use miRNA replacement to increase the expression of suppressed miRNAs. 
miRNA inhibitors are chemically modified single-stranded antisense oligonucleotides (ASOs) that are complementary to the mature miRNA. To date, angtagomiRs (target-single miRNAs conjugated with cholesterol), anti-miRs (target-single miRNAs) and tiny anti-miRs (target miRNA families) have been synthesized to mediate miRNA inhibition. These ASOs can reduce pathogenic expressed miRNAs [91,92].

Nonviral delivery of miRNAs, for example, using liposomes, nanoparticles, or antibodybased methods, as well as viral delivery such as adeno-associated virus (AAV) and adenovirus have been used for the restoration of microRNA levels.

Since various studies have shown that ncRNAs have the potential to regulate different cell pathways, one promising therapeutic goal could be to manipulate their function using oligonucleotide inhibitors or miR mimics. Antisense oligonucleotides directed against specific miR sequences are effectively taken up by diverse tissues. Furthermore, miR mimics and inhibitors are relatively stable in plasma and miR mimics and inhibitors are not highly toxic and can easily reach cellular gene targets. However, the challenge to directly target a specific inflamed tissue and/or a specific cell line is still ongoing $[87,88]$. It should be noted that some studies using anti-miR have shown that they can target plaque macrophages and regulate gene expression in these cells [91,92].

Non-coding RNAs, which are involved in stimulating and reducing the formation of foam cells, are summarized in Tables 1 and 2. 
Table 1. Non-coding RNAs that stimulate foam cell formation/function.

\begin{tabular}{|c|c|c|c|c|c|c|c|c|}
\hline \multirow{2}{*}{$\begin{array}{l}\text { Non-Coding } \\
\text { RNAs }\end{array}$} & \multirow{2}{*}{$\begin{array}{l}\text { Expression } \\
\text { Type }\end{array}$} & \multirow{2}{*}{$\begin{array}{l}\text { Target } \\
\text { Gene }\end{array}$} & \multirow{2}{*}{$\begin{array}{l}\text { Genetic Information } \\
\text { (Human) }\end{array}$} & \multicolumn{2}{|c|}{ Experimental Model } & \multirow{2}{*}{$\begin{array}{l}\text { Effect on Foam } \\
\text { Cell Formation }\end{array}$} & \multirow{2}{*}{$\begin{array}{l}\text { Regulation in Lipid } \\
\text { Metabolism }\end{array}$} & \multirow{2}{*}{ Reference } \\
\hline & & & & In Vivo & In Vitro & & & \\
\hline $\operatorname{miR}-144-3 p$ & & ABCA1 & $\begin{array}{l}\text { LXR and FXR control miR-144 } \\
\text { expression, with both causing an } \\
\text { upregulation in this miRNA }\end{array}$ & $\mathrm{ApoE}^{-/-}$mice & $\begin{array}{l}\text { human THP-1 } \\
\text { macrophage- } \\
\text { derived foam } \\
\text { cells }\end{array}$ & $\begin{array}{c}(+) \\
\text { Decrease } \\
\text { cholesterol efflux } \\
\text { to both apoAI and } \\
\text { HDL }\end{array}$ & $\begin{array}{l}\text { decreased HDL-C circulation } \\
\text { and impaired RCT in vivo } \\
\text { 144-3p mimics (agomir) } \\
\text { increases the expression of } \\
\text { inflammatory factors such as } \\
\text { IL-1b, IL- } 6 \text { and TNF- } \alpha \text { in vivo } \\
\text { and in vitro }\end{array}$ & [103] \\
\hline $\operatorname{miR}-33(a / b)$ & $\Uparrow$ & $\begin{array}{l}\text { ABCA1, } \\
\text { NPC1 } \\
\text { ABCG1 }\end{array}$ & $\begin{array}{l}\text { encoded within intron } 16 \text { of } \\
\text { SREBF2, a gene that encodes a } \\
\text { key transcriptional regulator of } \\
\text { cholesterol uptake and synthesis }\end{array}$ & $\begin{array}{c}\mathrm{miR}-33^{-/-} \\
\text {ApoE }^{-/-} \text {mice }\end{array}$ & $\begin{array}{l}\text { THP-1 } \\
\text { macrophage- } \\
\text { derived foam } \\
\text { cells }\end{array}$ & $\begin{array}{c}(+) \\
\text { Decrease } \\
\text { cholesterol efflux }\end{array}$ & $\begin{array}{c}\text { miR-33 coordinates } \\
\text { cholesterol homeostasis }\end{array}$ & {$[104,105]$} \\
\hline $\operatorname{miR}-19 b$ & $\Uparrow$ & ABCA1 & $\begin{array}{l}\text { located on chromosome } 13 \mathrm{q} 31.3 \\
\text { By an unknown mechanism, } \\
\text { expression was increased } \\
\text { compared with the control group } \\
\text { in advanced human } \\
\text { atherosclerotic plaques obtained } \\
\text { from patients during } \\
\text { endarterectomy }\end{array}$ & $\mathrm{ApoE}^{-/-}$mice & $\begin{array}{l}\text { human THP-1 } \\
\text { macrophage- } \\
\text { derived foam } \\
\text { cells }\end{array}$ & $\begin{array}{c}(+) \\
\text { Decrease } \\
\text { the efflux of } \\
\text { cholesterol to } \\
\text { apoAI }\end{array}$ & $\begin{array}{l}\text { Decrease the levels of HDL } \\
\text { (inhibitory role in RCT) }\end{array}$ & [106] \\
\hline $\operatorname{miR}-101$ & $\Uparrow$ & ABCA1 & $\begin{array}{l}\text { located on chromosome } \\
1 \text { p31.3 }\end{array}$ & - & $\begin{array}{l}\text { human } \\
\text { THP-1-derived } \\
\text { macrophages }\end{array}$ & $\begin{array}{c}(+) \\
\text { Decrease } \\
\text { the efflux of } \\
\text { cholesterol under } \\
\text { inflammatory } \\
\text { conditions }\end{array}$ & $\begin{array}{c}\text { regulates the availability of } \\
\text { free cholesterol for cellular } \\
\text { efflux by inhibiting } \\
\text { autophagy }\end{array}$ & [107] \\
\hline $\operatorname{miR}-378$ & $\Uparrow$ & ABCG1 & $\begin{array}{l}\text { The level of miR-378 in the aorta } \\
\text { is elevated during the } \\
\text { progression of atherosclerosis in } \\
\text { apoE } \text { a }^{-/} \text {mice }\end{array}$ & $\mathrm{ApoE}^{-/-}$mice & $\begin{array}{l}\text { ox-LDL-treated } \\
\text { human THP-1 } \\
\text { macrophages }\end{array}$ & $\begin{array}{c}(+) \\
\text { Decrease } \\
\text { cholesterol efflux }\end{array}$ & $\begin{array}{l}\text { activator protein-1/miRNA- } \\
378 / \text { ABCG1 is a novel } \\
\text { cascade for CoQ10 in } \\
\text { facilitating macrophage } \\
\text { cholesterol efflux in vitro and } \\
\text { in vivo }\end{array}$ & [108] \\
\hline
\end{tabular}


Table 1. Cont.

\begin{tabular}{|c|c|c|c|c|c|c|c|c|}
\hline \multirow{2}{*}{$\begin{array}{l}\text { Non-Coding } \\
\text { RNAs }\end{array}$} & \multirow{2}{*}{$\begin{array}{l}\text { Expression } \\
\text { Type }\end{array}$} & \multirow{2}{*}{$\begin{array}{l}\text { Target } \\
\text { Gene }\end{array}$} & \multirow{2}{*}{$\begin{array}{l}\text { Genetic Information } \\
\text { (Human) }\end{array}$} & \multicolumn{2}{|c|}{ Experimental Model } & \multirow{2}{*}{$\begin{array}{l}\text { Effect on Foam } \\
\text { Cell Formation }\end{array}$} & \multirow{2}{*}{$\begin{array}{l}\text { Regulation in Lipid } \\
\text { Metabolism }\end{array}$} & \multirow{2}{*}{ Reference } \\
\hline & & & & In Vivo & In Vitro & & & \\
\hline miR-302a & & ABCA1 & located on chromosome 4q25 & Ldlr $^{-/-}$mice & $\begin{array}{l}\text { primary human } \\
\text { and murine } \\
\text { macrophages }\end{array}$ & $\begin{array}{l}(+) \\
\begin{array}{c}\text { Decreases efflux of } \\
\text { cholesterol }\end{array}\end{array}$ & $\begin{array}{c}\text { inhibiting miR-302a in vivo } \\
\text { increases ABCA1 in aorta and } \\
\text { liver of Ldlr }{ }^{-/-} \text {mice } \\
\text { and increases circulating } \\
\text { HDL }\end{array}$ & [109] \\
\hline $\operatorname{miR}-27$ & $\Uparrow$ & $\begin{array}{l}\text { LPL, } \\
\text { ACAT1, } \\
\text { ABCA1 } \\
\text { CD36 }\end{array}$ & $\begin{array}{l}\text { located on chromosome } \\
9 \mathrm{q} 22\end{array}$ & - & $\begin{array}{l}\text { ox-LDL-treated } \\
\text { THP-1 } \\
\text { macrophages }\end{array}$ & $\begin{array}{c}(+) \\
\text { Reduced } \\
\text { cholesterol efflux } \\
\text { reduces } \\
\text { cholesteryl ester } \\
\text { formation } \\
\text { blocks lipid } \\
\text { uptake }\end{array}$ & $\begin{array}{l}\text { regulates the ratio of cellular } \\
\text { free cholesterol (FC) and } \\
\text { cholesterol ester (CE) in } \\
\text { THP-1 macrophages }\end{array}$ & [110] \\
\hline $\operatorname{miR}-26$ & $\Uparrow$ & $\begin{array}{r}\text { ARL7, } \\
\text { ABCA1 }\end{array}$ & $\begin{array}{l}\text { located on chromosome } \\
\text { 3p22.2 }\end{array}$ & - & $\begin{array}{l}\text { mouse and human } \\
\text { LXR activated } \\
\text { macrophages }\end{array}$ & $\begin{array}{c}(+) \\
\text { Downregulate } \\
\text { LXR dependent } \\
\text { cholesterol efflux }\end{array}$ & $\begin{array}{l}\text { blocks the expression of two } \\
\text { important LXR target genes } \\
\text { (ABCA1 and ARL7) required } \\
\text { for cholesterol efflux }\end{array}$ & [111] \\
\hline $\operatorname{miR}-134$ & $\Uparrow$ & ANGPTL4 & $\begin{array}{l}\text { located on chromosome } \\
14 \mathrm{q} 32.31\end{array}$ & - & $\begin{array}{c}\text { THP-1 } \\
\text { macrophages }\end{array}$ & $\begin{array}{c}(+) \\
\text { Increase } \\
\text { LPL-mediated } \\
\text { lipid accumulation }\end{array}$ & $\begin{array}{l}\text { By suppressing the } \\
\text { expression of ANGPTL4, } \\
\text { which is a regulator of } \\
\text { lipoprotein lipase (LPL) } \\
\text { activity, it promotes oxLDL } \\
\text { uptake and inflammatory } \\
\text { responses in vitro }\end{array}$ & [112] \\
\hline $\operatorname{miR}-155$ & $\Uparrow$ & HBP1 & $\begin{array}{l}\text { located within a region known as } \\
\text { the B-cell integration cluster (BIC) }\end{array}$ & $\mathrm{ApoE}^{-/-}$mice & $\begin{array}{l}\text { ox-LDL-treated } \\
\text { human THP-1 } \\
\text { macrophages }\end{array}$ & $\begin{array}{l}(+) \\
\text { Enhanced lipid } \\
\text { uptake and } \\
\text { enhanced ROS } \\
\text { production }\end{array}$ & $\begin{array}{l}\text { Silencing of miR-155 in } \\
\text { ApoE }-/- \text { mice } \\
\text { by injecting antagomiR-155 } \\
\text { decreased the lipid-laden } \\
\text { macrophages and the } \\
\text { formation of atherosclerotic } \\
\text { plaques }\end{array}$ & [113] \\
\hline
\end{tabular}


Table 1. Cont.

\begin{tabular}{|c|c|c|c|c|c|c|c|c|}
\hline \multirow{2}{*}{$\begin{array}{l}\text { Non-Coding } \\
\text { RNAs }\end{array}$} & \multirow{2}{*}{$\begin{array}{l}\text { Expression } \\
\text { Type }\end{array}$} & \multirow{2}{*}{$\begin{array}{l}\text { Target } \\
\text { Gene }\end{array}$} & \multirow{2}{*}{$\begin{array}{l}\text { Genetic Information } \\
\text { (Human) }\end{array}$} & \multicolumn{2}{|c|}{ Experimental Model } & \multirow{2}{*}{$\begin{array}{l}\text { Effect on Foam } \\
\text { Cell Formation }\end{array}$} & \multirow{2}{*}{$\begin{array}{l}\text { Regulation in Lipid } \\
\text { Metabolism }\end{array}$} & \multirow{2}{*}{ Reference } \\
\hline & & & & In Vivo & In Vitro & & & \\
\hline miR-216a & & CSE & located on chromosome 2p16.1 & - & $\begin{array}{l}\text { THP-1 } \\
\text { macrophages- } \\
\text { derived foam } \\
\text { cells }\end{array}$ & $\begin{array}{c}(+) \\
\text { Decreased ABCA1 } \\
\text { expression and } \\
\text { cholesterol efflux }\end{array}$ & $\begin{array}{c}\text { Downregulation of CSE/H2S } \\
\text { leads to an increase in } \\
\text { cholesterol accumulation in } \\
\text { foam cells }\end{array}$ & [114] \\
\hline $\operatorname{miR}-382-5 p$ & & NFIA & $\begin{array}{l}\text { located on chromosome } \\
14 \mathrm{q} 32.31\end{array}$ & - & $\begin{array}{l}\text { THP-1 } \\
\text { macrophage- } \\
\text { derived foam } \\
\text { cells }\end{array}$ & $\begin{array}{c}(+) \\
\text { Reduces } \\
\text { cholesterol efflux } \\
\text { Increases lipid } \\
\text { uptake }\end{array}$ & $\begin{array}{l}\text { RP5-833A20.1/miR-382- } \\
\text { 5p/NFIA pathway regulates } \\
\text { cholesterol homeostasis }\end{array}$ & [107] \\
\hline $\operatorname{miR}-486$ & & HAT1 & $\begin{array}{l}\text { located on chromosome } \\
\text { 8p11.21 }\end{array}$ & - & $\begin{array}{l}\text { THP-1 } \\
\text { macrophage- } \\
\text { derived foam } \\
\text { cells }\end{array}$ & $\begin{array}{c}(+) \\
\text { Reduces } \\
\text { cholesterol efflux }\end{array}$ & $\begin{array}{c}\text { HAT1 is capable of } \\
\text { acetylating H4K5 and H4K12 } \\
\text { and increasing ABCA1 } \\
\text { expression }\end{array}$ & [115] \\
\hline $\operatorname{miR-212}$ & $\Uparrow$ & SirT1 & $\begin{array}{l}\text { located on chromosome } \\
17 \mathrm{p} 13.3\end{array}$ & $\mathrm{ApoE}^{-/-}$mice & $\begin{array}{l}\text { THP-1 human } \\
\text { macrophages } \\
\text { treated with } \\
\text { oxLDL }\end{array}$ & $\begin{array}{c}(+) \\
\text { Suppresses } \\
\text { ABCA1 dependent } \\
\text { cholesterol efflux }\end{array}$ & $\begin{array}{c}\text { SIRT1 has capable of } \\
\text { inducing LXR activity to } \\
\text { increase ABCA1 expression in } \\
\text { human macrophages }\end{array}$ & [116] \\
\hline miR-19a & $\Uparrow$ & HBP-1 & $\begin{array}{l}\text { miR-19a is an important member } \\
\text { of the miR-17-92 polycistronic } \\
\text { gene cluster } \\
\text { MiR-19a is abundant in the blood } \\
\text { and tissues of patients with } \\
\text { atherosclerotic coronary artery } \\
\text { disease }\end{array}$ & $\mathrm{ApoE}^{-/-}$mice & $\begin{array}{l}\text { THP-1 derived } \\
\text { macrophages } \\
\text { RAW264.7 cells }\end{array}$ & $\begin{array}{c}(+) \\
\text { Increases lipid } \\
\text { uptake of } \\
\text { macrophages }\end{array}$ & $\begin{array}{l}\text { HBP-1 participates in } \\
\text { inhibiting the expression of } \\
\text { the macrophage migration } \\
\text { inhibitory factor (MIF) } \\
\text { and lipid uptake by } \\
\text { macrophages } \\
\text { size of the atherosclerotic } \\
\text { plaques in antagmiR-19a } \\
\text { treated mice was reduced }\end{array}$ & [117] \\
\hline $\operatorname{miR}-497$ & $\Uparrow$ & Apelin & Located on chromosome 17q13.1 & - & $\begin{array}{l}\text { Human THP-1 } \\
\text { macrophages } \\
\text { treated with } \\
\text { oxLDL }\end{array}$ & $\begin{array}{c}(+) \\
\text { Decrease } \\
\text { cholesterol efflux } \\
\text { to apoA-I. }\end{array}$ & $\begin{array}{l}\text { Apelin is an adipokine that is } \\
\text { involved in the } \\
\text { pathophysiology of } \\
\text { cardiovascular diseases }\end{array}$ & [118] \\
\hline
\end{tabular}


Table 1. Cont.

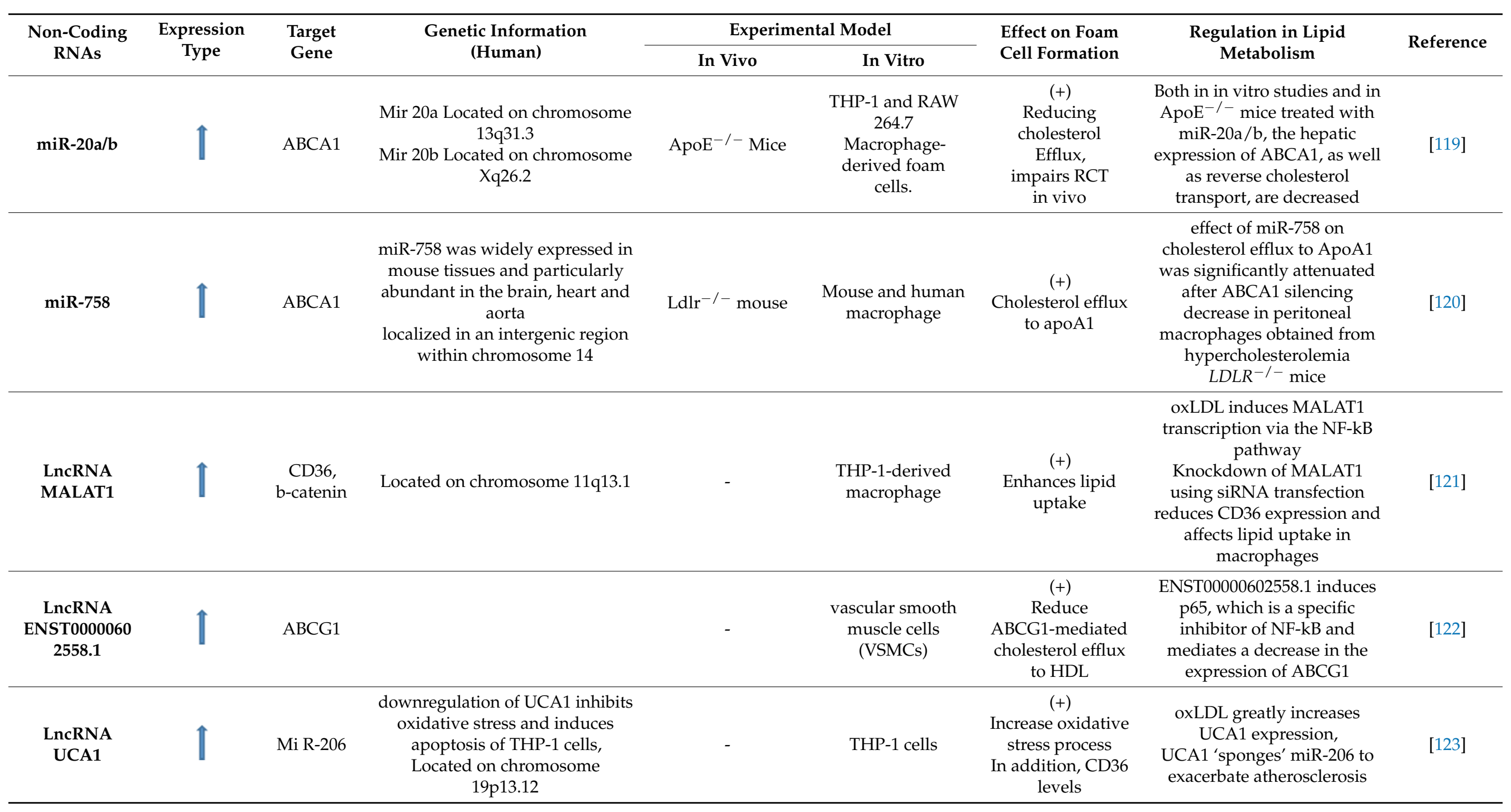


Table 2. Non-coding RNAs that attenuate foam cell formation/function.

\begin{tabular}{|c|c|c|c|c|c|c|c|c|}
\hline \multirow{2}{*}{$\begin{array}{l}\text { Non-Coding } \\
\text { RNA }\end{array}$} & \multirow{2}{*}{$\begin{array}{l}\text { Expression } \\
\text { Type }\end{array}$} & \multirow{2}{*}{ Target Gene } & \multirow{2}{*}{$\begin{array}{l}\text { Genetic Information } \\
\text { (Human) }\end{array}$} & \multicolumn{2}{|c|}{ Experimental Model } & \multirow{2}{*}{$\begin{array}{l}\text { Effect on Foam Cell } \\
\text { Formation }\end{array}$} & \multirow{2}{*}{$\begin{array}{l}\text { Regulation in Lipid } \\
\text { Metabolism }\end{array}$} & \multirow{2}{*}{ Reference } \\
\hline & & & & In Vivo & In Vitro & & & \\
\hline $\operatorname{miR}-1275$ & & ApoC2 & $\begin{array}{l}\text { located on } \\
\text { chromosome } \\
\text { 6p21.31 }\end{array}$ & - & $\begin{array}{l}\text { THP-1 derived } \\
\text { macrophages }\end{array}$ & $\begin{array}{l}(-) \\
\text { Inhibited the } \\
\text { cellular uptake of } \\
\text { Ox-LDL and lipid } \\
\text { accumulation }\end{array}$ & $\begin{array}{l}\text { ApoC2 most important cofactor } \\
\text { for LPL lipolytic activity }\end{array}$ & [124] \\
\hline miR-202-3p & & $\begin{array}{l}\text { SCARB2, } \\
\text { ABCG4, } \\
\text { NCEH1I }\end{array}$ & $\begin{array}{l}\text { located on } \\
\text { chromosome } \\
10 \mathrm{q} 26.3\end{array}$ & - & $\begin{array}{l}\text { Human THP-1 } \\
\text { macrophage- } \\
\text { derived foam } \\
\text { cell }\end{array}$ & $\begin{array}{l}(-) \\
\text { Attenuates lipid uptake } \\
\text { Enhances cholesterol } \\
\text { efflux }\end{array}$ & $\begin{array}{l}\text { Reduces the expression of } \\
\text { scavenger receptor SCARB2 } \\
\text { Increases the expression of } \\
\text { NCEH1 and ABCG4 }\end{array}$ & [125] \\
\hline miR-181a & & TLR4 & $\begin{array}{l}\text { located on } \\
\text { chromosome } \\
1 \mathrm{q} 32.1\end{array}$ & - & THP-1 & $\begin{array}{l}\text { Attenuates lipid uptake } \\
\text { and apoptosis and } \\
\text { inflammation }\end{array}$ & $\begin{array}{l}\text { Inhibits protein levels of CD36 } \\
\text { (scavenger receptor class B) }\end{array}$ & [126] \\
\hline miR-135a & & TLR4 & $\begin{array}{l}\text { located on } \\
\text { chromosome } \\
\text { 3p21.2 }\end{array}$ & - & $\begin{array}{l}\text { RAW264.7 and } \\
\text { MOVAS cells }\end{array}$ & $\begin{array}{l}(-) \\
\text { Attenuates lipid uptake } \\
\text { and inhibit oxidative } \\
\text { stress and vascular } \\
\text { inflammation }\end{array}$ & $\begin{array}{l}\text { Inhibits CD36 } \\
\text { expression }\end{array}$ & [127] \\
\hline $\operatorname{miR}-9$ & & ACAT1 & $\begin{array}{l}\text { located on } \\
\text { chromosome } \\
\text { 1q22 }\end{array}$ & - & $\begin{array}{l}\text { Human THP-1 } \\
\text { macrophage- } \\
\text { derived foam } \\
\text { cell }\end{array}$ & $\begin{array}{l}(-) \\
\text { Decrease the cholesterol } \\
\text { ester formation }\end{array}$ & $\begin{array}{l}\text { Reduces the levels of the ACAT1 } \\
\text { protein } \\
\text { (Acyl-coenzyme A:cholesterol } \\
\text { acyltransferase ) }\end{array}$ & [128] \\
\hline miR-21 & & $\begin{array}{l}\text { MKK3 } \\
\text { MERTK }\end{array}$ & $\begin{array}{l}\text { located on } \\
\text { chromosome } \\
\text { 17q23.1 }\end{array}$ & $\begin{array}{c}\mathrm{Ldlr}^{-/}-\text {or } \\
\text { miR } 21^{-/-} \text {mice }\end{array}$ & $\begin{array}{l}\text { Peritoneal } \\
\text { macrophages from } \\
\text { adult miR21-/- } \\
\text { mice }\end{array}$ & $\begin{array}{l}\qquad(-) \\
\text { Attenuated cholesterol } \\
\text { efflux and promoting } \\
\text { the lipid accumulation, } \\
\text { Reduce apoptotic cell } \\
\text { uptake }\end{array}$ & $\begin{array}{l}\text { Knock down of miR-21 increases } \\
\text { the expression of MKK3, } \\
\text { promoting the induction of } \\
\text { p38-CHOP and jNK signaling, } \\
\text { which results in degradation of } \\
\text { ABCG1, } \\
\text { Decreases expression of MERTK; } \\
\text { a key receptor that mediates the } \\
\text { clearance of apoptotic cells }\end{array}$ & [129] \\
\hline
\end{tabular}


Table 2. Cont.

\begin{tabular}{|c|c|c|c|c|c|c|c|c|}
\hline \multirow{2}{*}{$\begin{array}{l}\text { Non-Coding } \\
\text { RNA }\end{array}$} & \multirow{2}{*}{$\begin{array}{l}\text { Expression } \\
\text { Type }\end{array}$} & \multirow{2}{*}{ Target Gene } & \multirow{2}{*}{$\begin{array}{l}\text { Genetic Information } \\
\text { (Human) }\end{array}$} & \multicolumn{2}{|c|}{ Experimental Model } & \multirow{2}{*}{$\begin{array}{l}\text { Effect on Foam Cell } \\
\text { Formation }\end{array}$} & \multirow{2}{*}{$\begin{array}{l}\text { Regulation in Lipid } \\
\text { Metabolism }\end{array}$} & \multirow{2}{*}{ Reference } \\
\hline & & & & In Vivo & In Vitro & & & \\
\hline $\operatorname{miR-150}$ & & AdipoR2 & $\begin{array}{c}\text { located on } \\
\text { chromosome } \\
\text { 19q13.33 }\end{array}$ & - & $\begin{array}{c}\text { THP-1 } \\
\text { macrophages }\end{array}$ & $\begin{array}{c}(-) \\
\text { Attenuates lipid uptake } \\
\text { Increases cholesterol } \\
\text { efflux }\end{array}$ & $\begin{array}{c}\text { Decreases CD36, } \\
\text { upregulates } \\
\text { ABCA1 and ABCG1 via the } \\
\text { PPAR } \gamma \text { - and LXR } \alpha \text {-dependent } \\
\text { pathways. }\end{array}$ & [130] \\
\hline $\operatorname{miR}-133 a$ & & $\begin{array}{l}\text { TR4 } \\
\text { (testicular } \\
\text { orphan } \\
\text { nuclear } \\
\text { receptor 4) }\end{array}$ & $\begin{array}{l}\text { located on } \\
\text { chromosome } \\
\text { 18q11.2 }\end{array}$ & - & $\begin{array}{c}\text { RAW } 264.7 \\
\text { macrophage cells }\end{array}$ & $\begin{array}{c}(-) \\
\text { Decreased oxLDL } \\
\text { uptake } \\
\text { In addition, lipid } \\
\text { accumulation }\end{array}$ & Decreases expression of CD36 & [131] \\
\hline miR-155 & & $\begin{array}{l}\text { Tim-3, CEH } \\
\text { (cholesterol } \\
\text { ester } \\
\text { hydrolase) }\end{array}$ & $\begin{array}{l}\text { located on } \\
\text { chromosome } \\
21 \mathrm{q} 21.3\end{array}$ & - & THP-1 & $\begin{array}{c}(-) \\
\text { Increases cholesterol } \\
\text { efflux, } \\
\text { Decreased lipid uptake }\end{array}$ & $\begin{array}{l}\text { inhibits Tim- } 3 \text { expression and } \\
\text { increases the expression of CEH } \\
\text { resulting in increased expression } \\
\text { of ABCA1; } \\
\text { inhibits the expression of SR-A, }\end{array}$ & [132] \\
\hline $\operatorname{miR}-98$ & $\Uparrow$ & $\begin{array}{l}\text { LOX-1 } \\
\text { (Lectin-like } \\
\text { ox-LDL } \\
\text { scavenger } \\
\text { receptor-1) }\end{array}$ & $\begin{array}{l}\text { located on } \\
\text { chromosome } \\
\text { Xp11.22 }\end{array}$ & $\mathrm{ApoE}^{-/-}$mice & $\begin{array}{l}\text { Macrophages were } \\
\text { collected from } \\
\text { C57BL/6 mice }\end{array}$ & $\begin{array}{l}(-) \\
\text { Decreases the lipid } \\
\text { uptake and lipid } \\
\text { accumulation }\end{array}$ & decreases LOX-1 expression & [134] \\
\hline $\operatorname{miR}-223$ & $\Uparrow$ & $\begin{array}{l}\text { TLR4-NF-кB } \\
\text { signaling } \\
\text { pathway }\end{array}$ & $\begin{array}{c}\text { located on } \\
\text { chromosome } \\
\text { Xq12 }\end{array}$ & $\begin{array}{c}\text { ApoE }{ }^{-/-} \text {mouse, } \\
\text { C57BL/6J } \\
\text { wild-type } \\
\text { mice(control) }\end{array}$ & $\begin{array}{c}\text { Murine } \\
\text { macrophage cell } \\
\text { line RAW } 264.7\end{array}$ & $\begin{array}{c}(-) \\
\text { Increase cholesterol } \\
\text { efflux to apoA-I, } \\
\text { Decrease inflammation }\end{array}$ & $\begin{array}{l}\text { activates the PI3K/AKT } \\
\text { signaling pathway }\end{array}$ & [135] \\
\hline
\end{tabular}


Table 2. Cont.

\begin{tabular}{|c|c|c|c|c|c|c|c|c|}
\hline \multirow{2}{*}{$\begin{array}{l}\text { Non-Coding } \\
\text { RNA }\end{array}$} & \multirow{2}{*}{$\begin{array}{l}\text { Expression } \\
\text { Type }\end{array}$} & \multirow{2}{*}{ Target Gene } & \multirow{2}{*}{$\begin{array}{l}\text { Genetic Information } \\
\text { (Human) }\end{array}$} & \multicolumn{2}{|c|}{ Experimental Model } & \multirow{2}{*}{$\begin{array}{c}\text { Effect on Foam Cell } \\
\text { Formation }\end{array}$} & \multirow{2}{*}{$\begin{array}{l}\text { Regulation in Lipid } \\
\text { Metabolism }\end{array}$} & \multirow{2}{*}{ Reference } \\
\hline & & & & In Vivo & In Vitro & & & \\
\hline miR-23a & & HSP90 & $\begin{array}{l}\text { located on } \\
\text { chromosome } \\
19 p 13.12\end{array}$ & - & $\begin{array}{c}\text { THP-1 } \\
\text { macrophages }\end{array}$ & $\begin{array}{c}(-) \\
\text { Inhibit lipid } \\
\text { accumulation }\end{array}$ & $\begin{array}{l}\text { Decreased apoptosis of foam } \\
\text { cells; decreases inflammation } \\
\text { factors by inhibiting the } \\
\text { activation of NF- } \mathrm{kB} \text { pathways }\end{array}$ & [136] \\
\hline $\operatorname{miR}-146 b-5 p$ & & TRAF6 & $\begin{array}{l}\text { located on } \\
\text { chromosome } \\
10 \mathrm{q} 24.32\end{array}$ & - & $\begin{array}{l}\text { THP-1 human } \\
\text { monocytic and the } \\
\text { HEK293T human } \\
\text { embryonic kidney } \\
\text { cell line }\end{array}$ & $\begin{array}{c}(-) \\
\text { Decrease lipid uptake }\end{array}$ & $\begin{array}{c}\text { miR-146-5p inhibitor increases } \\
\text { TRAF6-mediated activation of } \\
\text { NF- } \mathrm{kB}(\mathrm{p} 65) \text { and } \\
\text { increases inflammatory response }\end{array}$ & [137] \\
\hline $\operatorname{miR}-221-3 p$ & $\Uparrow$ & ADAM22 & $\begin{array}{l}\text { located on } \\
\text { chromosome Xp11.3 }\end{array}$ & - & RAW264.7 & $\begin{array}{c}(-) \\
\text { Decrease lipid uptake }\end{array}$ & $\begin{array}{c}\text { Decreases CD36; decrease } \\
\text { oxidative stress and apoptosis }\end{array}$ & [138] \\
\hline $\operatorname{miR}-16$ & & $\begin{array}{l}\text { PDCD4 } \\
\text { (Programmed } \\
\text { cell death 4) }\end{array}$ & $\begin{array}{l}\text { located on } \\
\text { chromosome 13q14 }\end{array}$ & $\mathrm{ApoE}^{-/-}$mice & $\begin{array}{l}\text { macrophage- } \\
\text { derived foam cell } \\
\text { (RAW264.7) }\end{array}$ & $(-)$ & $\begin{array}{l}\text { Suppresses the activation of } \\
\text { inflammatory macrophages and } \\
\text { decreases release of inflammatory } \\
\text { cytokines via the MAPK and } \\
\text { NF- } \mathrm{kB} \text { pathways }\end{array}$ & [139] \\
\hline miR-34a & 凹 & $\begin{array}{c}\text { HDAC1 } \\
\text { (histone } \\
\text { deacetylase } \\
\text { 1) }\end{array}$ & $\begin{array}{c}\text { located on } \\
\text { chromosome 1p36.22 }\end{array}$ & $\begin{array}{l}\text { Male C57BL/6J } \\
\text { and ApoE } \\
\text { mice }\end{array}$ & $\begin{array}{c}\text { Human THP-1 } \\
\text { macrophages }\end{array}$ & $\begin{array}{c}(-) \\
\text { Prevents the } \\
\text { accumulation of } \\
\text { triglyceride and total } \\
\text { and free cholesterol }\end{array}$ & $\begin{array}{l}\text { Hyperhomocysteinemia (HHcy) } \\
\text { accelerates atherogenesis via } \\
\text { decreased expression of miR-34a }\end{array}$ & [140] \\
\hline Let-7g & $\Uparrow$ & $\begin{array}{l}\text { NF-кB } \\
\text { complex } \\
\text { MEKK1 }\end{array}$ & $\begin{array}{c}\text { located on } \\
\text { chromosome 3p21.2 }\end{array}$ & $\begin{array}{l}\text { ApoE }{ }^{-/-} \text {mouse, } \\
\text { IKK } \alpha \mathrm{f} / \mathrm{f}: \mathrm{MLysCre} / \\
\text { apoE }\end{array}$ & $\begin{array}{l}\text { Human } \\
\text { THP-1 } \\
\text { macrophage }\end{array}$ & $\begin{array}{c}(-) \\
\text { increase cholesterol } \\
\text { efflux, } \\
\text { Decrease intracellular } \\
\text { lipid accumulation }\end{array}$ & $\begin{array}{c}\text { up-regulates SREBF2, which is a } \\
\text { critical regulator of } \\
\text { cholesterol/lipid homeostasis, } \\
\text { up-regulates ABCA1 via } \\
\text { suppression of miR-33a, } \\
\text { decreases p53-dependent } \\
\text { apoptosis }\end{array}$ & [141] \\
\hline
\end{tabular}


Table 2. Cont.

\begin{tabular}{|c|c|c|c|c|c|c|c|c|}
\hline \multirow{2}{*}{$\begin{array}{l}\text { Non-Coding } \\
\text { RNA }\end{array}$} & \multirow{2}{*}{$\begin{array}{l}\text { Expression } \\
\text { Type }\end{array}$} & \multirow{2}{*}{ Target Gene } & \multirow{2}{*}{$\begin{array}{c}\text { Genetic Information } \\
\text { (Human) }\end{array}$} & \multicolumn{2}{|c|}{ Experimental Model } & \multirow{2}{*}{$\begin{array}{l}\text { Effect on Foam Cell } \\
\text { Formation }\end{array}$} & \multirow{2}{*}{$\begin{array}{l}\text { Regulation in Lipid } \\
\text { Metabolism }\end{array}$} & \multirow{2}{*}{ Reference } \\
\hline & & & & In Vivo & In Vitro & & & \\
\hline $\begin{array}{c}\text { LncRNA } \\
\text { CDKN2B-AS1 }\end{array}$ & $\|$ & ADAM10 & $\begin{array}{c}\text { located on } \\
\text { chromosome 9p21.3 }\end{array}$ & $\begin{array}{l}\text { ApoE } \\
\text { C57BL/6J Mice }\end{array}$ & $\begin{array}{l}\text { THP-1 } \\
\text { macrophage- } \\
\text { derived foam } \\
\text { cells }\end{array}$ & $\begin{array}{c}(-) \\
\text { Increases Cholesterol } \\
\text { Efflux, } \\
\text { Decrease lipid } \\
\text { accumulation }\end{array}$ & $\begin{array}{l}\text { Inhibits inflammatory responses } \\
\text { by suppressing the transcription } \\
\text { of ADAM10 }\end{array}$ & [142] \\
\hline $\begin{array}{c}\text { LncRNA } \\
\text { DYNLRB2-2 }\end{array}$ & $\Uparrow$ & miR-298 & $\begin{array}{c}\text { located on } \\
\text { chromosome 16q23.2 }\end{array}$ & - & $\begin{array}{l}\text { THP-1 } \\
\text { macrophage- } \\
\text { derived foam } \\
\text { cells }\end{array}$ & $\begin{array}{c}(-) \\
\text { Impairing oxLDL } \\
\text { uptake, } \\
\text { increases cholesterol } \\
\text { efflux }\end{array}$ & $\begin{array}{l}\text { Induces autophagy by activating } \\
\text { the LKB1/AMPK/mTOR } \\
\text { signaling pathway via the } \\
\text { miR-298/SIRT3 axis; } \\
\text { decreases the expression of TLR2 } \\
\text { and enhances the expression of } \\
\text { ABCA1 }\end{array}$ & [143] \\
\hline
\end{tabular}




\section{Non-Coding RNAs That Stimulate Foam Cell Formation/Function}

Most of the microRNAs described in this review, either directly or indirectly, target ABCA1.

As mentioned above, $\mathrm{ABCA} 1$ is a membrane protein at the cell surface that regulates the transport of cholesterol and phospholipid and other metabolites [144]. In general, deficiency or downregulation of ABCA1 expression leads to a significant decrease in serum HDL levels and an increased risk of atherosclerosis. This is primarily due to the suppression of cholesterol efflux and disruption of the reverse cholesterol transport (RCT) cycle and subsequent foam cell formation. HDL has a cardioprotective role by preventing the oxidation of lipoproteins and returning cholesterol from peripheral tissues back to the liver via the RCT process [145].

Protein levels and ABCA1 activity are regulated at both the transcriptional and posttranscriptional levels, such that any downregulation of ABCA1 expression adversely affects the function of atheroprotective lipoprotein subclasses. Additionally, in $\mathrm{APOE}^{-/-}$mice, the overexpression of ABCA1 can effectively reduce the size of atherosclerotic plaques [146,147].

Direct and indirect effects of different Non-coding RNAs on the expression of ABCA1 are shown in Figure 2.

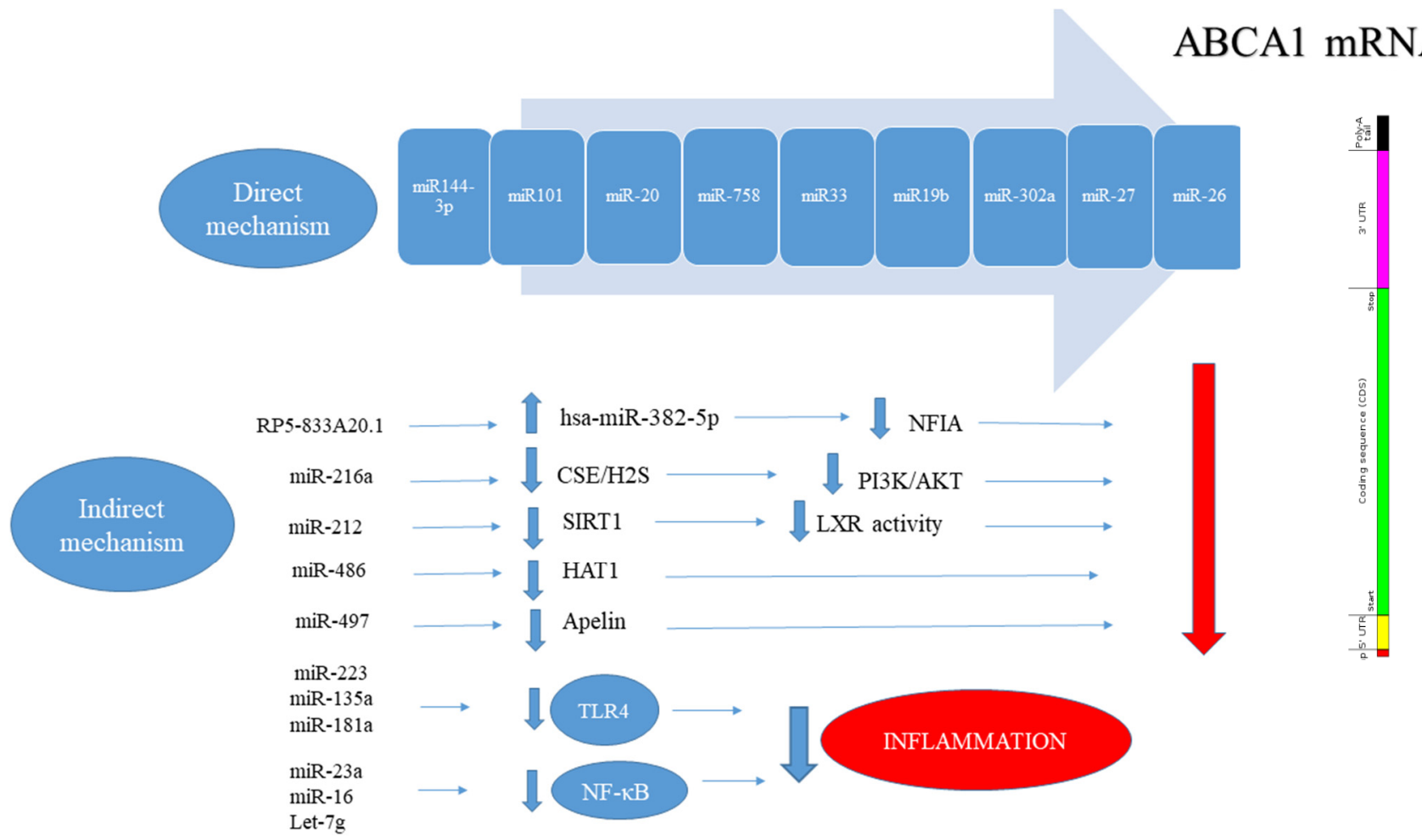

Figure 2. Direct and indirect effects of different Non-coding RNAs on the expression of ABCA1, which has a large $3^{\prime} \mathrm{UTR}$ region and is one of the most important transporters in cholesterol efflux [144,145]. In direct mechanism: non-coding RNAs able to bind to $3^{\prime} \mathrm{UTR}$ of ABCA1 mRNA transcript which ABCA1 expression regulate, in indirect mechanism: non-coding RNAs were not able to bind to $3^{\prime} \mathrm{UTR}$ of ABCA1 mRNA transcript although these noncoding RNAs that bind to $3^{\prime} \mathrm{UTR}$ of other mRNA transcript in turn regulate ABCA1 expression. It has also been shown that reducing inflammation increases the expression of this transporter and has a negative role in the formation of foam cells by increasing cholesterol efflux [148,149].

Some microRNA, such as miR-33 [104], miR-19b [106], miR-101 [106], miR-144$3 p$ [106], miR-302a [104], miR-26 [106], miR-20a/b [106] and miR-758 [106] directly target the $3^{\prime}$ UTR of ABCA1 in macrophages, which suppresses ABCA1 expression and disrupts cholesterol homeostasis. The disruption in cholesterol homeostasis occurs due to a decrease in the efflux of cholesterol to ApoA1 or HDL, which ultimately causes the formation of foam cells. A more detailed description is given in Table 1. 


\section{1. $m i R-33$}

This microRNA directly targets ABCA1 and ABCG1 in murine and human macrophages and downregulates these transporters, which leads to lower cellular cholesterol efflux and increased cholesterol accumulation and foam cell formation. In human cells, miR-33 neither downregulated the expression of ABCG1, nor interfered with cholesterol efflux to HDL in human THP-1 macrophages, which is consistent with the lack of miR-33-binding sites in the human ABCG1 3'UTR [150-152]. In a study using double-knockout miR-33 $3^{-/-}, \mathrm{ApoE}^{-/-}$ mice, cholesterol efflux increased and plaque size decreased compared to control mice. Moreover, it was demonstrated that the use of microRNA-33 antagonism increased ABCA1 expression in vitro and in vivo and increased cholesterol efflux to ApoA1 [105,152,153]. In another study, the silencing of miR-33 with antisense oligonucleotides (anti-miR-33) in $\mathrm{LDLR}^{-/-}$mice for 14 weeks did not affect lesion formation and the progression of atherosclerosis and failed to maintain elevated plasma HDL-cholesterol (HDL-C) [104]. This is probably because previous regression studies employed mice that received antimiRs for only 4 weeks, as well as the existence of homeostatic compensatory mechanisms controlling plasma HDL. Additionally, the discrepancy between experimental designs, including the dietary composition, the gender of the mice and the possible influence of the intestinal microbiome may vary between the two models [154]. There is evidence suggesting athero-protective effects of hematopoietic loss of miR-33 including decreased number of apoptotic cells and decreased size of the necrotic cores in plaques from mice transplanted with $\mathrm{miR}-33^{-/-}$bone marrow, indicative of enhanced plaque stability. Moreover, upregulation of MERTK experssion, a kinase involved in the regulation of efferocytosis, increases ABCA1 expression, MQs cholesterol efflux capacity and RCT and decreases the accumulation of cholesterol esters (CEs) in MQs in vivo. Furthermore, loss of miR-33 remarkably decreases the amount of MQ phosphatidylethanolamines (PEs) and phosphatidylserine (PS). These changes may have important effects such as attenuating NFKB activation and innate immune response [155].

Despite athero-protective effect of anti-miR-33 therapies, global deletion of miR-33 results in disturbed responsiveness to insulin in multiple metabolic organs including the liver, white adipose tissue (WAT) and skeletal muscle through TAGs, DAGs and ceramides accumulation, PKC activation and inhibition of ERK activity. Furthermore, alterations in feeding behavior are mainly responsible for the obesity in miR-33 $3^{-/-}$mice. Since the hypothalamic POMC and AgRP neurons, which regulate food intake, are also GABAergic neurons, they may be directly influenced by alterations in miR-33. This could elucidate some of the differences between genetic and pharmacological inhibition of miR-33, as antimiR-33 therapeutics would not be expected to pass the blood-brain barrier [156].

\section{2. $m i R-27 a / b$}

The miR-27 family has two isoforms; namely, miR-27a, which is an intergenic miRNA, and miR-27b, which is an intronic miRNA. miR-27a/b has been reported to regulate several genes involved in lipid metabolism, including PPARs and RXRs, which can activate the transcription of many target genes in vivo, including SR-BI, ABCG1 and ABCA1 [157]. This miRNA, by repressing CD36 expression in THP-1 macrophages, regulates cholesterol uptake. Additionally, miR-27a/b reduces the expression of ACAT1 (involved in the formation of foam cells via re-esterification of excess FC as a means to increase CEs), which, in turn, leads to a decrease in the formation of CEs in THP-1 macrophage-derived foam cells [157]. To maintain the homeostasis of cholesterol in macrophages, intracellular CE is hydrolyzed to $\mathrm{FC}$ as the initial step for the efflux of excess cholesterol, which occurs via the $\mathrm{ABC}$ transporters $\mathrm{ABCA} 1$ and $\mathrm{ABCG} 1$, as well as other non-transporter pathways such as SR-B1 [157]. Moreover, miR-27a/b inhibits LPL expression, which is involved in lipid uptake in vitro and in vivo. Importantly, this miRNA also regulates HDL-mediated cholesterol efflux in human foam cells without targeting SRBI and ABCG1, which probably indirectly affects the PPAR/RXR pathway. Additionally, miR-27a/b inhibits cholesterol 
efflux from macrophages via reduction in the expression of $A B C A 1$ and subsequently causing a decrease in ApoA1 [110,158,159].

Some microRNAs, such as miR-216a [114,160], miR-486 [114,160], miR-212 [114,160], miR-497 [114,160] and LncRNA ENST00000602558.1 [118], also indirectly decrease the expression of the ABCA1 gene. The details are provided in Table 1.

\section{3. $m i R-216 a$}

The expression of this particular miRNA has been shown to be increased in myocardial biopsies from patients with ischemic heart failure [161].

It is known that the cystathionine gamma-lyase/hydrogen sulfide $\left(\mathrm{CSE} / \mathrm{H}_{2} \mathrm{~S}\right)$ enzymatic reaction in the trans-sulfuration pathway (a pathway that generates endogenous $\mathrm{H}_{2} \mathrm{~S}$ ) increases ABCA1 expression in foam cell [160,162-164].

Specifically, miR-216a directly targets the $3^{\prime} \mathrm{UTR}$ of CSE, which is one of the two key enzymes in endogenous $\mathrm{H}_{2} \mathrm{~S}$ production. The $\mathrm{CSE} / \mathrm{H}_{2} \mathrm{~S}$ system has an anti-atherosclerotic role in the cardiovascular system. Downregulation of the $\mathrm{CSE} / \mathrm{H}_{2} \mathrm{~S}$ enzymatic reaction pathway results in decreased $\mathrm{ABCA} 1$ expression due to a reduction in the phosphorylation of PI3K and AKT, which subsequently leads to an increase in cholesterol accumulation in foam cells $[114,160]$.

\section{4. $m i R-382-5 p$}

The RP5-833A20.1/miR-382-5p/NFIA pathway is essential for the regulation of cholesterol homeostasis and inflammatory responses. Interestingly, RP5-833A20.1 has been shown to decrease nuclear factor IA (NFIA) expression through the hsa-miR-382-5p pathway. NFIA is essential for adipocyte differentiation and lipid droplet formation. Specifically, NFIA inhibits atherosclerotic plaque formation in $\mathrm{ApoE}^{-/-}$mice by increasing RCT and decreasing circulating cytokine levels. Overexpression of miR-382-5p causes a reduction in the expression of NFIA, as well as decreases the expression of ABCA1 and ABCG1 and increases the expression of SRA1, CD36 and NFKB $[107,165]$. In vivo studies with miR-382-5p have not been performed to date.

\section{Non-Coding RNAs That Attenuate Foam Cell Formation}

It has been shown that some non-coding RNAs are involved in macrophage cholesterol homeostasis by acting on inflammatory pathways. Studies have shown that miR-181a [126], miR-135a [126] and miR-223 [126], target TLR4 and reduce its expression. Thisprocess regulates cholesterol homeostasis in macrophages by reducing inflammation, reducing lipid uptake and increasing cholesterol efflux. Within macrophages, MiR-23a [126], miR16 [126] and Let-7g [126] have an inhibitory effect on NF-kB pathways, which regulate lipid metabolism by reducing inflammation. The details are summarized in Table 2.

\section{1. $m i R-150$}

MiR-150 has been shown to be upregulated in a human monocyte cell line in response to oxLDL treatment. Overexpression of this microRNA was proven to decrease the endogenous expression of AdipoR2 in macrophages, which promotes cholesterol efflux by the upregulation of ABCA1 and ABCG1. This process occurs via the PPAR $\gamma$ - and LXR $\alpha$ dependent signaling pathways and decreases CD36 and intracellular lipid accumulation.

Since miR-150 can be packaged into microvesicles (MVs) and secreted from monocytes, MVs isolated from the plasma of patients with atherosclerosis have been determined to possess greater amounts of miR-150 than those from healthy donors. This finding may be explained by the fact that during the pathogenesis of atherosclerosis, stimulation of monocytes to release MVs that contain miRNAs, such as miR-150, can prevent lipid accumulation and foam cell formation [130].

\section{2. $m i R-155$}

Dual effects of miR-155 on macrophages in the context of atherosclerosis. 
miR-155 is a "multi-target" molecule specifically expressed in atherosclerotic plaques and pro-inflammatory macrophages [166]. The effects of miR-155 on atherogenesis have been controversial, because it exerts dual effects on both inflammatory and apoptotic pathways in lesional macrophages. miR-155 can enhance or prevent lesion formation relevant to the "stage" of atherosclerosis. Nazari-Jahantigh et al. reported that miR-155 was anti-atherogenic in the early stage of atherosclerosis, but became pro-atherogenic as the lesions progressed to a more advanced stage [167]. OxLDL induces miR-155 expression in human macrophages, which is essential for lipid uptake and ROS production by macrophages [168]. The use of antagomiR- 155 has been shown to reduce lipid levels in human macrophages and decrease the size of plaques in $\mathrm{ApoE}^{-/-}$mice. Elevated miR155 levels increase oxLDL-induced foam cell formation by targeting HBP1. In addition, miR-155 expression is downregulated by the YY1/HDACs complex [113].

Another study showed that miR-155 mimics enhanced the expression of $\mathrm{CEH}$ at both the transcriptional and translational level in a dose- and time-dependent manner in human foam cells, although this effect may have occurred due to the inhibition in the expression of Tim-3, since overexpression of Tim-3 can inhibit the expression of CEH. Additionally, using a human monocyte cell line, it has been demonstrated that the overexpression of miR-155 can significantly inhibit the expression of SR-A, decrease lipid accumulation, increase the expression of ABCA1 and thereby increase cholesterol efflux [132].

A study also found that NF- $k B$ transcription factor, which is activated by TNF- $\alpha$, binds to the miR-155 promoter and stimulates transcription of miR-155. Accordingly, the expression of calcium-regulated heat-stable protein 1 (CARHSP1) is decreased. This is significant, because CARHSP1 enhances the stability of TNF- $\alpha$ mRNA, which is important for the efficient production of TNF- $\alpha$. Furthermore, it has been demonstrated in a human monocyte cell line that miR-155 indirectly decreases TNF- $\alpha$ expression, decreases macrophage inflammation and lipid uptake and decreases foam cell formation [133].

\section{Conclusions}

Atherosclerosis is a chronic disease with a network of complex pathological processes. One of the primary mechanisms involved in this disease is the formation of foam cells, which leads to the growth and rupture of atherosclerotic plaques and finally, to its clinical manifestations (MI and stroke) [12,169]. Noncoding RNAs play an important role in various aspects of atherogenesis including foam cell formation. For example, many studies using noncoding RNAs have targeted different aspects of foam cell formation, such as cholesterol uptake, storage and efflux, indicating the well-established and effective role of non-coding RNAs, particularly miRNAs, in foam cell formation. Noncoding RNAs, especially miRNAs such, as miR-33, miR-27ab and miR-144, can have a pro-atherosclerotic role by stimulating foam cell formation, while others, such as miR-150, miR-1275 and Let-7g, exert an atheroprotective role by suppressing foam cell formation. miR-155 has shown conflicting results in different studies.

Clinical work performed using miRNAs has focused primarily on the inhibition of miRNAs through antisense oligonucleotides that complement targeting mRNA. For example, anti-miR oligonucleotides, modified antimiR oligonucleotides, anti-miR peptides, or the use of genetic vectors to replace miRs, such as with miR mimics, have been used [87-90]. Today, many preclinical studies have investigated the therapeutic anti-atherosclerotic potential of miRNAs by using miR mimics or their antagonists, which have shown promising results. These findings indicate that miRNA targeted therapy may represent a novel approach for the treatment of atherosclerosis. However, chronic treatment or genetic ablation of some of these miRNAs (miR-33), has been found to result in adverse effects including obesity and insulin resistance [156].

There are also limitations to using miRNAs, including their multifunctionality and their role in different biological processes. Moreover, there are few specific miRNAs in a tissue or organ, so most of the miRNAs affect unselected or non-targeted tissues. One of the major drawbacks to the therapeutic use of microRNAs in atherosclerosis is the 
fact that many molecules of this class have additional unwanted side effects and studies on the interaction between different miRNAs are relatively scarce. Secondly, miRNAs target prediction tools are not completely accurate and false positive and false negative predictions are still an issue of concern. Lastly, the full scope of elucidating their functions in vivo is limited and this fact impedes the investigation of the most interesting primatespecific non-coding RNAs in widely used atherosclerotic mouse models. Furthermore, the discrepancies in anatomy, lipid metabolism and gene expression complicate the translation of experimental results obtained in mice to humans.

Author Contributions: All authors were involved in the conception, design, drafting, revision and final approval of this review. All authors have read and agreed to the published version of the manuscript.

Funding: This research received no external funding.

Conflicts of Interest: Maciej Banach: speakers bureau: Abbott/Mylan, Abbott Vascular, Actavis, Akcea, Amgen, Biofarm, KRKA, MSD, Polpharma, Sanofi Aventis, Servier and Valeant; consultant to Abbott Vascular, Akcea, Amgen, Daichii Sankyo, Esperion, Freia Pharmaceuticals, Lilly, MSD, Polfarmex, Resverlogix, Sanofi-Aventis; Grants from Sanofi and Valeant. All other authors declare no conflict of interest.

\section{References}

1. Wakabayashi, I. Associations between alcohol drinking and multiple risk factors for atherosclerosis in smokers and nonsmokers. Angiology 2010, 61, 495-503. [CrossRef] [PubMed]

2. Sitia, S.; Tomasoni, L.; Atzeni, F.; Ambrosio, G.; Cordiano, C.; Catapano, A.; Tramontana, S.; Perticone, F.; Naccarato, P.; Camici, P. From endothelial dysfunction to atherosclerosis. Autoimmun. Rev. 2010, 9, 830-834. [CrossRef] [PubMed]

3. Gliozzi, M.; Scicchitano, M.; Bosco, F.; Musolino, V.; Carresi, C.; Scarano, F.; Maiuolo, J.; Nucera, S.; Maretta, A.; Paone, S. Modulation of nitric oxide synthases by oxidized LDLs: Role in vascular inflammation and atherosclerosis development. Int. J. Mol. Sci. 2019, 20, 3294. [CrossRef] [PubMed]

4. Cyr, A.R.; Huckaby, L.V.; Shiva, S.S.; Zuckerbraun, B.S. Nitric Oxide and Endothelial Dysfunction. Crit. Care Clin. 2020, 36, 307-321. [CrossRef]

5. Liu, W.; Yin, Y.; Zhou, Z.; He, M.; Dai, Y. OxLDL-induced IL-1beta secretion promoting foam cells formation was mainly via CD36 mediated ROS production leading to NLRP3 inflammasome activation. Inflamm. Res. 2014, 63, 33-43. [CrossRef]

6. Daub, K.; Seizer, P.; Stellos, K.; Krämer, B.F.; Bigalke, B.; Schaller, M.; Fateh-Moghadam, S.; Gawaz, M.; Lindemann, S. Oxidized LDL-activated platelets induce vascular inflammation. In Seminars in Thrombosis and Hemostasis; Thieme Medical Publishers: New York, NY, USA, 2010; pp. 146-156.

7. Chávez-Sánchez, L.; Espinosa-Luna, J.E.; Chávez-Rueda, K.; Legorreta-Haquet, M.V.; Montoya-Díaz, E.; Blanco-Favela, F. Innate immune system cells in atherosclerosis. Arch. Med. Res. 2014, 45, 1-14. [CrossRef] [PubMed]

8. Kiyan, Y.; Tkachuk, S.; Hilfiker-Kleiner, D.; Haller, H.; Fuhrman, B.; Dumler, I. oxLDL induces inflammatory responses in vascular smooth muscle cells via urokinase receptor association with CD36 and TLR4. J. Mol. Cell. Cardiol. 2014, 66, 72-82. [CrossRef]

9. Seo, J.-W.; Yang, E.-J.; Yoo, K.-H.; Choi, I.-H. Macrophage differentiation from monocytes is influenced by the lipid oxidation degree of low density lipoprotein. Mediat. Inflamm. 2015, 2015, 235797. [CrossRef]

10. Rios, F.J.; Koga, M.M.; Pecenin, M.; Ferracini, M.; Gidlund, M.; Jancar, S. Oxidized LDL induces alternative macrophage phenotype through activation of CD36 and PAFR. Mediat. Inflamm. 2013, 2013, 198193. [CrossRef] [PubMed]

11. Wolfs, I.M.; Donners, M.M.; de Winther, M.P. Differentiation factors and cytokines in the atherosclerotic plaque micro-environment as a trigger for macrophage polarisation. Thromb. Haemost. 2011, 106, 763-771. [CrossRef]

12. Maguire, E.M.; Pearce, S.W.; Xiao, Q. Foam cell formation: A new target for fighting atherosclerosis and cardiovascular disease. Vasc. Pharmacol. 2019, 112, 54-71. [CrossRef]

13. Moore, K.J.; Sheedy, F.J.; Fisher, E.A. Macrophages in atherosclerosis: A dynamic balance. Nat. Rev. Immunol. 2013, 13, 709-721. [CrossRef]

14. Vainio, S.; Ikonen, E. Macrophage cholesterol transport: A critical player in foam cell formation. Ann. Med. 2003, 35, 146-155. [CrossRef] [PubMed]

15. Birck, M.M.; Saraste, A.; Hyttel, P.; Odermarsky, M.; Liuba, P.; Saukko, P.; Hansen, A.K.; Pesonen, E. Endothelial cell death and intimal foam cell accumulation in the coronary artery of infected hypercholesterolemic minipigs. J. Cardiovasc. Transl. Res. 2013, 6, 579-587. [CrossRef] [PubMed]

16. Chen, C.; Khismatullin, D.B. Oxidized low-density lipoprotein contributes to atherogenesis via co-activation of macrophages and mast cells. PLoS ONE 2015, 10, e0123088. [CrossRef] [PubMed]

17. Galis, Z.S.; Sukhova, G.K.; Lark, M.W.; Libby, P. Increased expression of matrix metalloproteinases and matrix degrading activity in vulnerable regions of human atherosclerotic plaques. J. Clin. Investig. 1994, 94, 2493-2503. [CrossRef] 
18. Hultgårdh-Nilsson, A.; Durbeej, M. Role of the extracellular matrix and its receptors in smooth muscle cell function: Implications in vascular development and disease. Curr. Opin. Lipidol. 2007, 18, 540-545. [CrossRef]

19. Wezel, A.; Lagraauw, H.M.; van der Velden, D.; de Jager, S.C.; Quax, P.H.; Kuiper, J.; Bot, I. Mast cells mediate neutrophil recruitment during atherosclerotic plaque progression. Atherosclerosis 2015, 241, 289-296. [CrossRef]

20. Van der Donckt, C.; Van Herck, J.L.; Schrijvers, D.M.; Vanhoutte, G.; Verhoye, M.; Blockx, I.; Van Der Linden, A.; Bauters, D.; Lijnen, H.R.; Sluimer, J.C. Elastin fragmentation in atherosclerotic mice leads to intraplaque neovascularization, plaque rupture, myocardial infarction, stroke, and sudden death. Eur. Heart J. 2015, 36, 1049-1058. [CrossRef]

21. Choudhury, R.P.; Lee, J.M.; Greaves, D.R. Mechanisms of disease: Macrophage-derived foam cells emerging as therapeutic targets in atherosclerosis. Nat. Clin. Pract. Cardiovasc. Med. 2005, 2, 309-315. [CrossRef]

22. Peters, W.; Charo, I.F. Involvement of chemokine receptor 2 and its ligand, monocyte chemoattractant protein-1, in the development of atherosclerosis: Lessons from knockout mice. Curr. Opin. Lipidol. 2001, 12, 175-180. [CrossRef]

23. Greaves, D.R.; Gordon, S. Thematic review series: The immune system and atherogenesis. Recent insights into the biology of macrophage scavenger receptors. J. Lipid Res. 2005, 46, 11-20. [CrossRef] [PubMed]

24. Combadière, C.; Potteaux, S.; Rodero, M.; Simon, T.; Pezard, A.; Esposito, B.; Merval, R.; Proudfoot, A.; Tedgui, A.; Mallat, Z. Combined inhibition of CCL2, CX3CR1, and CCR5 abrogates Ly6C(hi) and Ly6C(lo) monocytosis and almost abolishes atherosclerosis in hypercholesterolemic mice. Circulation 2008, 117, 1649-1657. [CrossRef] [PubMed]

25. Smith, J.D.; Trogan, E.; Ginsberg, M.; Grigaux, C.; Tian, J.; Miyata, M. Decreased atherosclerosis in mice deficient in both macrophage colony-stimulating factor (op) and apolipoprotein E. Proc. Natl. Acad. Sci. USA 1995, 92, 8264-8268. [CrossRef] [PubMed]

26. Cipriani, S.; Francisci, D.; Mencarelli, A.; Renga, B.; Schiaroli, E.; D’Amore, C.; Baldelli, F.; Fiorucci, S. Efficacy of the CCR5 antagonist maraviroc in reducing early, ritonavir-induced atherogenesis and advanced plaque progression in mice. Circulation 2013, 127, 2114-2124. [CrossRef] [PubMed]

27. Fotis, L.; Agrogiannis, G.; Vlachos, I.S.; Pantopoulou, A.; Margoni, A.; Kostaki, M.; Verikokos, C.; Tzivras, D.; Mikhailidis, D.P.; Perrea, D. Intercellular adhesion molecule (ICAM)-1 and vascular cell adhesion molecule (VCAM)-1 at the early stages of atherosclerosis in a rat model. In Vivo 2012, 26, 243-250.

28. Ley, K.; Huo, Y. VCAM-1 is critical in atherosclerosis. J. Clin. Investig. 2001, 107, 1209-1210. [CrossRef]

29. Serebruany, V.; Malinin, A.; Scott, R. The in vitro effects of a novel vascular protectant, AGI-1067, on platelet aggregation and major receptor expression in subjects with multiple risk factors for vascular disease. J. Cardiovasc. Pharmacol. Ther. 2006, 11, 191-196. [CrossRef]

30. Rahaman, S.O.; Lennon, D.J.; Febbraio, M.; Podrez, E.A.; Hazen, S.L.; Silverstein, R.L. A CD36-dependent signaling cascade is necessary for macrophage foam cell formation. Cell Metab. 2006, 4, 211-221. [CrossRef]

31. Coller, S.P.; Paulnock, D.M. Signaling pathways initiated in macrophages after engagement of type A scavenger receptors. J. Leukoc. Biol. 2001, 70, 142-148.

32. Sikorski, K.; Czerwoniec, A.; Bujnicki, J.M.; Wesoly, J.; Bluyssen, H.A. STAT1 as a novel therapeutical target in pro-atherogenic signal integration of IFN $\gamma$, TLR4 and IL-6 in vascular disease. Cytokine Growth Factor Rev. 2011, 22, 211-219. [CrossRef]

33. De Vos, J.; Mathijs, I.; Xavier, C.; Massa, S.; Wernery, U.; Bouwens, L.; Lahoutte, T.; Muyldermans, S.; Devoogdt, N. Specific targeting of atherosclerotic plaques in $\mathrm{ApoE}^{-/-}$mice using a new camelid sdAb binding the vulnerable plaque marker LOX-1. Mol. Imaging Biol. 2014, 16, 690-698. [CrossRef] [PubMed]

34. Xu, S.; Ogura, S.; Chen, J.; Little, P.J.; Moss, J.; Liu, P. LOX-1 in atherosclerosis: Biological functions and pharmacological modifiers. Cell. Mol. Life Sci. 2013, 70, 2859-2872. [CrossRef] [PubMed]

35. Mäkinen, P.I.; Lappalainen, J.P.; Heinonen, S.E.; Leppänen, P.; Lähteenvuo, M.T.; Aarnio, J.V.; Heikkilä, J.; Turunen, M.P.; Ylä-Herttuala, S. Silencing of either SR-A or CD36 reduces atherosclerosis in hyperlipidaemic mice and reveals reciprocal upregulation of these receptors. Cardiovasc. Res. 2010, 88, 530-538. [CrossRef] [PubMed]

36. Dai, X.-Y.; Cai, Y.; Mao, D.-D.; Qi, Y.-F.; Tang, C.; Xu, Q.; Zhu, Y.; Xu, M.-J.; Wang, X. Increased stability of phosphatase and tensin homolog by intermedin leading to scavenger receptor A inhibition of macrophages reduces atherosclerosis in apolipoprotein E-deficient mice. J. Mol. Cell. Cardiol. 2012, 53, 509-520. [CrossRef]

37. Sakashita, N.; Miyazaki, A.; Takeya, M.; Horiuchi, S.; Chang, C.C.; Chang, T.-Y.; Takahashi, K. Localization of human acylcoenzyme A: Cholesterol acyltransferase-1 (ACAT-1) in macrophages and in various tissues. Am. J. Pathol. 2000, 156, 227-236. [CrossRef]

38. Sekiya, M.; Osuga, J.-I.; Igarashi, M.; Okazaki, H.; Ishibashi, S. The role of neutral cholesterol ester hydrolysis in macrophage foam cells. J. Atheroscler. Thromb. 2011, 18, 359-364. [CrossRef] [PubMed]

39. McLaren, J.E.; Michael, D.R.; Ashlin, T.G.; Ramji, D.P. Cytokines, macrophage lipid metabolism and foam cells: Implications for cardiovascular disease therapy. Prog. Lipid Res. 2011, 50, 331-347. [CrossRef]

40. Fazio, S.; Linton, M. Mouse models of hyperlipidemia and atherosclerosis. Front. Biosci 2001, 6, D515-D525. [CrossRef]

41. Ikenoya, M.; Yoshinaka, Y.; Kobayashi, H.; Kawamine, K.; Shibuya, K.; Sato, F.; Sawanobori, K.; Watanabe, T.; Miyazaki, A. A selective ACAT-1 inhibitor, K-604, suppresses fatty streak lesions in fat-fed hamsters without affecting plasma cholesterol levels. Atherosclerosis 2007, 191, 290-297. [CrossRef] 
42. Perrey, S.; Legendre, C.; Matsuura, A.; Guffroy, C.; Binet, J.; Ohbayashi, S.; Tanaka, T.; Ortuno, J.C.; Matsukura, T.; Laugel, T. Preferential pharmacological inhibition of macrophage ACAT increases plaque formation in mouse and rabbit models of atherogenesis. Atherosclerosis 2001, 155, 359-370. [CrossRef]

43. Sekiya, M.; Yamamuro, D.; Ohshiro, T.; Honda, A.; Takahashi, M.; Kumagai, M.; Sakai, K.; Nagashima, S.; Tomoda, H.; Igarashi, M. Absence of Nceh1 augments 25-hydroxycholesterol-induced ER stress and apoptosis in macrophages. J. Lipid Res. 2014, 55, 2082-2092. [CrossRef] [PubMed]

44. Chistiakov, D.A.; Bobryshev, Y.V.; Orekhov, A.N. Macrophage-mediated cholesterol handling in atherosclerosis. J. Cell. Mol. Med. 2016, 20, 17-28. [CrossRef] [PubMed]

45. Chistiakov, D.A.; Melnichenko, A.A.; Myasoedova, V.A.; Grechko, A.V.; Orekhov, A.N. Mechanisms of foam cell formation in atherosclerosis. J. Mol. Med. 2017, 95, 1153-1165. [CrossRef]

46. Silva, J.C.; César, F.A.; de Oliveira, E.M.; Turato, W.M.; Tripodi, G.L.; Castilho, G.; Machado-Lima, A.; de las Heras, B.; Boscá, L.; Rabello, M.M. New PPAR $\gamma$ partial agonist improves obesity-induced metabolic alterations and atherosclerosis in LDLr ${ }^{-/-}$mice. Pharmacol. Res. 2016, 104, 49-60. [CrossRef]

47. Li, A.C.; Binder, C.J.; Gutierrez, A.; Brown, K.K.; Plotkin, C.R.; Pattison, J.W.; Valledor, A.F.; Davis, R.A.; Willson, T.M.; Witztum, J.L. Differential inhibition of macrophage foam-cell formation and atherosclerosis in mice by PPAR $\alpha, \beta / \delta$, and $\gamma$. J. Clin. Investig. 2004, 114, 1564-1576. [CrossRef] [PubMed]

48. Phillips, M.C. Molecular mechanisms of cellular cholesterol efflux. J. Biol. Chem. 2014, 289, 24020-24029. [CrossRef]

49. Joyce, C.W.; Wagner, E.M.; Basso, F.; Amar, M.J.; Freeman, L.A.; Shamburek, R.D.; Knapper, C.L.; Syed, J.; Wu, J.; Vaisman, B.L. ABCA1 overexpression in the liver of LDLr-KO mice leads to accumulation of pro-atherogenic lipoproteins and enhanced atherosclerosis. J. Biol. Chem. 2006, 281, 33053-33065. [CrossRef]

50. Van Eck, M.; Bos, I.S.T.; Hildebrand, R.B.; Van Rij, B.T.; Van Berkel, T.J. Dual role for scavenger receptor class B, type I on bone marrow-derived cells in atherosclerotic lesion development. Am. J. Pathol. 2004, 165, 785-794. [CrossRef]

51. Wang, H.; Yang, Y.; Chen, H.; Dan, J.; Cheng, J.; Guo, S.; Sun, X.; Wang, W.; Ai, Y.; Li, S. The predominant pathway of apoptosis in THP-1 macrophage-derived foam cells induced by 5-aminolevulinic acid-mediated sonodynamic therapy is the mitochondria-caspase pathway despite the participation of endoplasmic reticulum stress. Cell. Physiol. Biochem. 2014, 33, 1789-1801. [CrossRef]

52. Tabas, I. Macrophage apoptosis in atherosclerosis: Consequences on plaque progression and the role of endoplasmic reticulum stress. Antioxid. Redox Signal. 2009, 11, 2333-2339. [CrossRef]

53. Newby, A.C.; George, S.J.; Ismail, Y.; Johnson, J.L.; Sala-Newby, G.B.; Thomas, A.C. Vulnerable atherosclerotic plaque metalloproteinases and foam cell phenotypes. Thromb. Haemost. 2009, 101, 1006-1011.

54. Tousoulis, D.; Oikonomou, E.; Economou, E.K.; Crea, F.; Kaski, J.C. Inflammatory cytokines in atherosclerosis: Current therapeutic approaches. Eur. Heart J. 2016, 37, 1723-1732. [CrossRef]

55. Chistiakov, D.A.; Melnichenko, A.A.; Grechko, A.V.; Myasoedova, V.A.; Orekhov, A.N. Potential of anti-inflammatory agents for treatment of atherosclerosis. Exp. Mol. Pathol. 2018, 104, 114-124. [CrossRef]

56. Tabas, I. Consequences and therapeutic implications of macrophage apoptosis in atherosclerosis: The importance of lesion stage and phagocytic efficiency. Arterioscler. Thromb. Vasc. Biol. 2005, 25, 2255-2264. [CrossRef]

57. Liu, J.; Thewke, D.P.; Su, Y.R.; Linton, M.F.; Fazio, S.; Sinensky, M.S. Reduced macrophage apoptosis is associated with accelerated atherosclerosis in low-density lipoprotein receptor-null mice. Arterioscler. Thromb. Vasc. Biol. 2005, 25, 174-179. [CrossRef] [PubMed]

58. Thorp, E.; Li, Y.; Bao, L.; Yao, P.M.; Kuriakose, G.; Rong, J.; Fisher, E.A.; Tabas, I. Brief report: Increased apoptosis in advanced atherosclerotic lesions of Apoe ${ }^{-/-}$mice lacking macrophage Bcl-2. Arterioscler. Thromb. Vasc. Biol. 2009, 29, 169-172. [CrossRef] [PubMed]

59. Arai, S.; Shelton, J.M.; Chen, M.; Bradley, M.N.; Castrillo, A.; Bookout, A.L.; Mak, P.A.; Edwards, P.A.; Mangelsdorf, D.J.; Tontonoz, P. A role for the apoptosis inhibitory factor AIM/Sp $\alpha /$ Api6 in atherosclerosis development. Cell Metab. 2005, 1, 201-213. [CrossRef]

60. Grainger, D.J.; Reckless, J.; McKilligin, E. Apolipoprotein E modulates clearance of apoptotic bodies in vitro and in vivo, resulting in a systemic proinflammatory state in apolipoprotein E-deficient mice. J. Immunol. 2004, 173, 6366-6375. [CrossRef] [PubMed]

61. Nagata, S. Apoptosis and clearance of apoptotic cells. Annu. Rev. Immunol. 2018, 36, 489-517. [CrossRef]

62. Kratzer, A.; Buchebner, M.; Pfeifer, T.; Becker, T.M.; Uray, G.; Miyazaki, M.; Miyazaki-Anzai, S.; Ebner, B.; Chandak, P.G.; Kadam, R.S. Synthetic LXR agonist attenuates plaque formation in apoE ${ }^{-/}$mice without inducing liver steatosis and hypertriglyceridemia. J. Lipid Res. 2009, 50, 312-326. [CrossRef] [PubMed]

63. Zahuczky, G.; Kristóf, E.; Majai, G.; Fésüs, L. Differentiation and glucocorticoid regulated apopto-phagocytic gene expression patterns in human macrophages. Role of Mertk in enhanced phagocytosis. PLoS ONE 2011, 6, e21349. [CrossRef] [PubMed]

64. Majai, G.; Sarang, Z.; Csomós, K.; Zahuczky, G.; Fésüs, L. PPAR $\gamma$-dependent regulation of human macrophages in phagocytosis of apoptotic cells. Eur. J. Immunol. 2007, 37, 1343-1354. [CrossRef] [PubMed]

65. Rosenblat, M.; Volkova, N.; Aviram, M. Pomegranate phytosterol ( $\beta$-sitosterol) and polyphenolic antioxidant (punicalagin) addition to statin, significantly protected against macrophage foam cells formation. Atherosclerosis 2013, 226, 110-117. [CrossRef] [PubMed] 
66. Uitz, E.; Bahadori, B.; McCarty, M.F.; Moghadasian, M.H. Practical strategies for modulating foam cell formation and behavior. World J. Clin. Cases WJCC 2014, 2, 497. [CrossRef] [PubMed]

67. Laufs, U.; Endres, M.; Custodis, F.; Gertz, K.; Nickenig, G.; Liao, J.K.; Böhm, M. Suppression of endothelial nitric oxide production after withdrawal of statin treatment is mediated by negative feedback regulation of rho GTPase gene transcription. Circulation 2000, 102, 3104-3110. [CrossRef]

68. Afshari, A.R.; Mollazadeh, H.; Henney, N.C.; Jamialahmad, T.; Sahebkar, A. Effects of statins on brain tumors: A review. Semin. Cancer Biol. 2020. [CrossRef]

69. Bagheri, H.; Ghasemi, F.; Barreto, G.E.; Sathyapalan, T.; Jamialahmadi, T.; Sahebkar, A. The effects of statins on microglial cells to protect against neurodegenerative disorders: A mechanistic review. BioFactors 2020, 46, 309-325. [CrossRef]

70. Gorabi, A.M.; Kiaie, N.; Pirro, M.; Bianconi, V.; Jamialahmadi, T.; Sahebkar, A. Effects of statins on the biological features of mesenchymal stem cells and therapeutic implications. Heart Fail. Rev. 2020. [CrossRef]

71. Kouhpeikar, H.; Delbari, Z.; Sathyapalan, T.; Simental-Mendía, L.E.; Jamialahmadi, T.; Sahebkar, A. The Effect of Statins through Mast Cells in the Pathophysiology of Atherosclerosis: A Review. Curr. Atheroscler. Rep. 2020, 22, 19. [CrossRef]

72. Mollazadeh, H.; Tavana, E.; Fanni, G.; Bo, S.; Banach, M.; Pirro, M.; von Haehling, S.; Jamialahmadi, T.; Sahebkar, A. Effects of statins on mitochondrial pathways. J. Cachexia Sarcopenia Muscle 2021. [CrossRef] [PubMed]

73. Sahebkar, A.; Serban, C.; Mikhailidis, D.P.; Undas, A.; Lip, G.Y.H.; Muntner, P.; Bittner, V.; Ray, K.K.; Watts, G.F.; Hovingh, G.K.; et al. Association between statin use and plasma d-dimer levels: A systematic review and meta-analysis of randomised controlled trials. Thromb. Haemost. 2015, 114, 546-557. [CrossRef]

74. Sahebkar, A.; Serban, C.; Ursoniu, S.; Mikhailidis, D.P.; Undas, A.; Lip, G.Y.H.; Bittner, V.; Ray, K.K.; Watts, G.F.; Kees Hovingh, G.; et al. The impact of statin therapy on plasma levels of von Willebrand factor antigen: Systematic review and meta-analysis of Randomised placebo-controlled trials. Thromb. Haemost. 2016, 115, 520-532. [CrossRef] [PubMed]

75. Serban, C.; Sahebkar, A.; Ursoniu, S.; Mikhailidis, D.P.; Rizzo, M.; Lip, G.Y.H.; Kees Hovingh, G.; Kastelein, J.J.P.; Kalinowski, L.; Rysz, J.; et al. A systematic review and meta-analysis of the effect of statins on plasma asymmetric dimethylarginine concentrations. Sci. Rep. 2015, 5, 1-8. [CrossRef]

76. Thomas, A.C.; Eijgelaar, W.J.; Daemen, M.J.; Newby, A.C. Foam cell formation in vivo converts macrophages to a pro-fibrotic phenotype. PLOS ONE 2015, 10, e0128163. [CrossRef]

77. Peeters, W.; Moll, F.L.; Vink, A.; van der Spek, P.J.; de Kleijn, D.P.; de Vries, J.-P.P.; Verheijen, J.H.; Newby, A.C.; Pasterkamp, G. Collagenase matrix metalloproteinase- 8 expressed in atherosclerotic carotid plaques is associated with systemic cardiovascular outcome. Eur. Heart J. 2011, 32, 2314-2325. [CrossRef] [PubMed]

78. Laxton, R.C.; Hu, Y.; Duchene, J.; Zhang, F.; Zhang, Z.; Leung, K.-Y.; Xiao, Q.; Scotland, R.S.; Hodgkinson, C.P.; Smith, K. A role of matrix metalloproteinase-8 in atherosclerosis. Circ. Res. 2009, 105, 921-929. [CrossRef]

79. Luttun, A.; Lutgens, E.; Manderveld, A.; Maris, K.; Collen, D.; Carmeliet, P.; Moons, L. Loss of matrix metalloproteinase-9 or matrix metalloproteinase-12 protects apolipoprotein E-deficient mice against atherosclerotic media destruction but differentially affects plaque growth. Circulation 2004, 109, 1408-1414. [CrossRef]

80. Johnson, J.L.; George, S.J.; Newby, A.C.; Jackson, C.L. Divergent effects of matrix metalloproteinases 3, 7, 9, and 12 on atherosclerotic plaque stability in mouse brachiocephalic arteries. Proc. Natl. Acad. Sci. USA 2005, 102, 15575-15580. [CrossRef]

81. Daub, K.; Langer, H.; Seizer, P.; Stellos, K.; May, A.E.; Goyal, P.; Bigalke, B.; Schönberger, T.; Geisler, T.; Siegel-Axel, D. Platelets induce differentiation of human CD34+ progenitor cells into foam cells and endothelial cells. FASEB J. 2006, 20, 2559-2561. [CrossRef] [PubMed]

82. Feng, Y.; Schouteden, S.; Geenens, R.; Van Duppen, V.; Herijgers, P.; Holvoet, P.; Van Veldhoven, P.P.; Verfaillie, C.M. Hematopoietic stem/progenitor cell proliferation and differentiation is differentially regulated by high-density and low-density lipoproteins in mice. PLoS ONE 2012, 7, e47286. [CrossRef]

83. Allahverdian, S.; Chehroudi, A.C.; McManus, B.M.; Abraham, T.; Francis, G.A. Contribution of intimal smooth muscle cells to cholesterol accumulation and macrophage-like cells in human atherosclerosis. Circulation 2014, 129, 1551-1559. [CrossRef] [PubMed]

84. Feil, S.; Fehrenbacher, B.; Lukowski, R.; Essmann, F.; Schulze-Osthoff, K.; Schaller, M.; Feil, R. Transdifferentiation of vascular smooth muscle cells to macrophage-like cells during atherogenesis. Circ. Res. 2014, 115, 662-667. [CrossRef]

85. Yu, B.; Wong, M.M.; Potter, C.M.; Simpson, R.M.; Karamariti, E.; Zhang, Z.; Zeng, L.; Warren, D.; Hu, Y.; Wang, W. Vascular stem/progenitor cell migration induced by smooth muscle cell-derived chemokine (C-C Motif) ligand 2 and chemokine (C-X-C motif) ligand 1 contributes to neointima formation. Stem Cells 2016, 34, 2368-2380. [CrossRef] [PubMed]

86. Ivan, L.; Antohe, F. Hyperlipidemia induces endothelial-derived foam cells in culture. J. Recept. Signal. Transduct. 2010, 30, 106-114. [CrossRef]

87. Xu, S.; Kamato, D.; Little, P.J.; Nakagawa, S.; Pelisek, J.; Jin, Z.G. Targeting epigenetics and non-coding RNAs in atherosclerosis: From mechanisms to therapeutics. Pharmacol. Ther. 2019, 196, 15-43. [CrossRef]

88. Uszczynska-Ratajczak, B.; Lagarde, J.; Frankish, A.; Guigó, R.; Johnson, R. Towards a complete map of the human long non-coding RNA transcriptome. Nat. Rev. Genet. 2018, 19, 535-548. [CrossRef]

89. Qureshi, I.A.; Mehler, M.F. Emerging roles of non-coding RNAs in brain evolution, development, plasticity and disease. Nat. Rev. Neurosci. 2012, 13, 528-541. [CrossRef] [PubMed] 
90. Fatica, A.; Bozzoni, I. Long non-coding RNAs: New players in cell differentiation and development. Nat. Rev. Genet. 2014, 15, 7-21. [CrossRef] [PubMed]

91. Engels, B.M.; Hutvagner, G. Principles and effects of microRNA-mediated post-transcriptional gene regulation. Oncogene 2006, 25, 6163-6169. [CrossRef] [PubMed]

92. Beermann, J.; Piccoli, M.-T.; Viereck, J.; Thum, T. Non-coding RNAs in development and disease: Background, mechanisms, and therapeutic approaches. Physiol. Rev. 2016, 96, 1297-1325. [CrossRef]

93. Cech, T.R.; Steitz, J.A. The noncoding RNA revolution-Trashing old rules to forge new ones. Cell 2014, 157, 77-94. [CrossRef] [PubMed]

94. Bartel, D.P. MicroRNAs: Target recognition and regulatory functions. Cell 2009, 136, 215-233. [CrossRef] [PubMed]

95. Lee, Y.; Kim, M.; Han, J.; Yeom, K.H.; Lee, S.; Baek, S.H.; Kim, V.N. MicroRNA genes are transcribed by RNA polymerase II. EMBO J. 2004, 23, 4051-4060. [CrossRef]

96. Cai, X.; Hagedorn, C.H.; Cullen, B.R. Human microRNAs are processed from capped, polyadenylated transcripts that can also function as mRNAs. RNA 2004, 10, 1957-1966. [CrossRef] [PubMed]

97. Ruby, J.G.; Jan, C.H.; Bartel, D.P. Intronic microRNA precursors that bypass Drosha processing. Nature 2007, 448, 83-86. [CrossRef] [PubMed]

98. Derrien, T.; Johnson, R.; Bussotti, G.; Tanzer, A.; Djebali, S.; Tilgner, H.; Guernec, G.; Martin, D.; Merkel, A.; Knowles, D.G. The GENCODE v7 catalog of human long noncoding RNAs: Analysis of their gene structure, evolution, and expression. Genome Res. 2012, 22, 1775-1789. [CrossRef] [PubMed]

99. Ulitsky, I.; Bartel, D.P. lincRNAs: Genomics, evolution, and mechanisms. Cell 2013, 154, 26-46. [CrossRef]

100. Batista, P.J.; Chang, H.Y. Long noncoding RNAs: Cellular address codes in development and disease. Cell 2013, 152, 1298-1307. [CrossRef]

101. Gong, C.; Maquat, L.E. IncRNAs transactivate STAU1-mediated mRNA decay by duplexing with $3^{\prime}$ UTRs via Alu elements. Nature 2011, 470, 284-288. [CrossRef]

102. Magny, E.G.; Pueyo, J.I.; Pearl, F.M.; Cespedes, M.A.; Niven, J.E.; Bishop, S.A.; Couso, J.P. Conserved regulation of cardiac calcium uptake by peptides encoded in small open reading frames. Science 2013, 341, 1116-1120. [CrossRef]

103. Hu, Y.W.; Hu, Y.R.; Zhao, J.Y.; Li, S.F.; Ma, X.; Wu, S.G.; Lu, J.B.; Qiu, Y.R.; Sha, Y.H.; Wang, Y.C.; et al. An agomir of miR-144$3 p$ accelerates plaque formation through impairing reverse cholesterol transport and promoting pro-inflammatory cytokine production. PLoS ONE 2014, 9, e94997. [CrossRef] [PubMed]

104. Marquart, T.J.; Wu, J.; Lusis, A.J.; Baldán, Á. Anti-miR-33 therapy does not alter the progression of atherosclerosis in low-density lipoprotein receptor-deficient mice. Arterioscler. Thromb. Vasc. Biol. 2013, 33, 455-458. [CrossRef] [PubMed]

105. Rotllan, N.; Ramírez, C.M.; Aryal, B.; Esau, C.C.; Fernández-Hernando, C. Therapeutic silencing of microRNA-33 inhibits the progression of atherosclerosis in Ldlr ${ }^{-/}$mice-Brief report. Arterioscler. Thromb. Vasc. Biol. 2013, 33, 1973-1977. [CrossRef]

106. Lv, Y.-C.; Tang, Y.-Y.; Peng, J.; Zhao, G.-J.; Yang, J.; Yao, F.; Ouyang, X.-P.; He, P.-P.; Xie, W.; Tan, Y.-L. MicroRNA-19b promotes macrophage cholesterol accumulation and aortic atherosclerosis by targeting ATP-binding cassette transporter A1. Atherosclerosis 2014, 236, 215-226. [CrossRef] [PubMed]

107. Zhang, N.; Lei, J.; Lei, H.; Ruan, X.; Liu, Q.; Chen, Y.; Huang, W. MicroRNA-101 overexpression by IL-6 and TNF- $\alpha$ inhibits cholesterol efflux by suppressing ATP-binding cassette transporter A1 expression. Exp. Cell Res. 2015, 336, 33-42. [CrossRef] [PubMed]

108. Wang, D.; Yan, X.; Xia, M.; Yang, Y.; Li, D.; Li, X.; Song, F.; Ling, W. Coenzyme Q10 promotes macrophage cholesterol efflux by regulation of the activator protein-1/miR-378/ATP-binding cassette transporter G1-signaling pathway. Arterioscler. Thromb. Vasc. Biol. 2014, 34, 1860-1870. [CrossRef]

109. Meiler, S.; Baumer, Y.; Toulmin, E.; Seng, K.; Boisvert, W.A. MicroRNA 302a is a novel modulator of cholesterol homeostasis and atherosclerosis. Arterioscler. Thromb. Vasc. Biol. 2015, 35, 323-331. [CrossRef]

110. Zhang, M.; Wu, J.-F.; Chen, W.-J.; Tang, S.-L.; Mo, Z.-C.; Tang, Y.-Y.; Li, Y.; Wang, J.-L.; Liu, X.-Y.; Peng, J. MicroRNA-27a/b regulates cellular cholesterol efflux, influx and esterification/hydrolysis in THP-1 macrophages. Atherosclerosis 2014, 234, 54-64. [CrossRef] [PubMed]

111. Sun, D.; Zhang, J.; Xie, J.; Wei, W.; Chen, M.; Zhao, X. MiR-26 controls LXR-dependent cholesterol efflux by targeting ABCA1 and ARL7. FEBS Lett. 2012, 586, 1472-1479. [CrossRef]

112. Lan, G.; Xie, W.; Li, L.; Zhang, M.; Liu, D.; Tan, Y.-L.; Cheng, H.-P.; Gong, D.; Huang, C.; Zheng, X.-L. MicroRNA-134 actives lipoprotein lipase-mediated lipid accumulation and inflammatory response by targeting angiopoietin-like 4 in THP-1 macrophages. Biochem. Biophys. Res. Commun. 2016, 472, 410-417. [CrossRef]

113. Tian, F.-J.; An, L.-N.; Wang, G.-K.; Zhu, J.-Q.; Li, Q.; Zhang, Y.-Y.; Zeng, A.; Zou, J.; Zhu, R.-F.; Han, X.-S. Elevated microRNA-155 promotes foam cell formation by targeting HBP1 in atherogenesis. Cardiovasc. Res. 2014, 103, 100-110. [CrossRef]

114. Gong, D.; Cheng, H.-P.; Xie, W.; Zhang, M.; Liu, D.; Lan, G.; Huang, C.; Zhao, Z.-W.; Chen, L.-Y.; Yao, F. Cystathionine $\gamma$-lyase (CSE)/hydrogen sulfide system is regulated by miR-216a and influences cholesterol efflux in macrophages via the PI3K/AKT/ABCA1 pathway. Biochem. Biophys. Res. Commun. 2016, 470, 107-116. [CrossRef] [PubMed]

115. Liu, D.; Zhang, M.; Xie, W.; Lan, G.; Cheng, H.-P.; Gong, D.; Huang, C.; Lv, Y.-C.; Yao, F.; Tan, Y.-L. MiR-486 regulates cholesterol efflux by targeting HAT1. Biochem. Biophys. Res. Commun. 2016, 472, 418-424. [CrossRef] [PubMed] 
116. Miao, H.; Zeng, H.; Gong, H. microRNA-212 promotes lipid accumulation and attenuates cholesterol efflux in THP-1 human macrophages by targeting SIRT1. Gene 2018, 643, 55-60. [CrossRef]

117. Chen, H.; Li, X.; Liu, S.; Gu, L.; Zhou, X. MircroRNA-19a promotes vascular inflammation and foam cell formation by targeting HBP-1 in atherogenesis. Sci. Rep. 2017, 7, 1-10. [CrossRef] [PubMed]

118. Cui, J.; Ren, Z.; Zou, W.; Jiang, Y. miR-497 accelerates oxidized low-density lipoprotein-induced lipid accumulation in macrophages by repressing the expression of apelin. Cell Biol. Int. 2017, 41, 1012-1019. [CrossRef] [PubMed]

119. Liang, B.; Wang, X.; Song, X.; Bai, R.; Yang, H.; Yang, Z.; Xiao, C.; Bian, Y. MicroRNA-20a/b regulates cholesterol efflux through post-transcriptional repression of ATP-binding cassette transporter A1. Biochim. Biophys. Acta BBA Mol. Cell Biol. Lipids 2017, 1862, 929-938. [CrossRef]

120. Ramirez, C.; Dávalos, A.; Goedeke, L.; Salerno, A.; Warrier, N.; Cirera-Salinas, D.; Suárez, Y.; Fernández-Hernando, C. miR-758 regulates cholesterol efflux through post-transcriptional repression of ABCA1. Arter. Thromb Vasc. Biol. 2011, 31, 2707-2714. [CrossRef]

121. Huangfu, N.; Xu, Z.; Zheng, W.; Wang, Y.; Cheng, J.; Chen, X. LncRNA MALAT1 regulates oxLDL-induced CD36 expression via activating $\beta$-catenin. Biochem. Biophys. Res. Commun. 2018, 495, 2111-2117. [CrossRef]

122. Cai, C.; Zhu, H.; Ning, X.; Li, L.; Yang, B.; Chen, S.; Wang, L.; Lu, X.; Gu, D. LncRNA ENST00000602558. 1 regulates ABCG1 expression and cholesterol efflux from vascular smooth muscle cells through a p65-dependent pathway. Atherosclerosis 2019, 285, 31-39. [CrossRef] [PubMed]

123. Hu, X.; Ma, R.; Fu, W.; Zhang, C.; Du, X. LncRNA UCA1 sponges miR-206 to exacerbate oxidative stress and apoptosis induced by ox-LDL in human macrophages. J. Cell. Physiol. 2019, 234, 14154-14160. [CrossRef] [PubMed]

124. Li, L.; Xu, W.; Fu, X.; Huang, Y.; Wen, Y.; Xu, Q.; He, X.; Wang, K.; Huang, S.; Lv, Z. Blood miR-1275 is associated with risk of ischemic stroke and inhibits macrophage foam cell formation by targeting ApoC2 gene. Gene 2020, 731, 144364. [CrossRef] [PubMed]

125. Li, L.; Wu, F.; Xie, Y.; Xu, W.; Xiong, G.; Xu, Y.; Huang, S.; Wu, Y.; Jiang, X. MiR-202-3p Inhibits Foam Cell Formation and is Associated with Coronary Heart Disease Risk in a Chinese Population. Int. Heart J. 2020, 61, 153-159. [CrossRef]

126. Du, X.J.; Lu, J.M.; Sha, Y. MiR-181a inhibits vascular inflammation induced by ox-LDL via targeting TLR4 in human macrophages. J. Cell. Physiol. 2018, 233, 6996-7003. [CrossRef]

127. Du, X.J.; Lu, J.M. MiR-135a represses oxidative stress and vascular inflammatory events via targeting toll-like receptor 4 in atherogenesis. J. Cell. Biochem. 2018, 119, 6154-6161. [CrossRef]

128. Xu, J.; Hu, G.; Lu, M.; Xiong, Y.; Li, Q.; Chang, C.C.; Song, B.; Chang, T.; Li, B. MiR-9 reduces human acyl-coenzyme A: Cholesterol acyltransferase-1 to decrease THP-1 macrophage-derived foam cell formation. Acta Biochim. Biophys. Sin. 2013, 45, 953-962. [CrossRef]

129. Canfrán-Duque, A.; Rotllan, N.; Zhang, X.; Fernández-Fuertes, M.; Ramírez-Hidalgo, C.; Araldi, E.; Daimiel, L.; Busto, R.; Fernández-Hernando, C.; Suárez, Y. Macrophage deficiency of miR-21 promotes apoptosis, plaque necrosis, and vascular inflammation during atherogenesis. EMBO Mol. Med. 2017, 9, 1244-1262. [CrossRef]

130. Li, J.; Zhang, S. microRNA-150 inhibits the formation of macrophage foam cells through targeting adiponectin receptor 2. Biochem. Biophys. Res. Commun. 2016, 476, 218-224. [CrossRef]

131. Peng, X.-P.; Huang, L.; Liu, Z.-H. miRNA-133a attenuates lipid accumulation via TR4-CD36 pathway in macrophages. Biochimie 2016, 127, 79-85. [CrossRef]

132. Zhang, F.; Zhao, J.; Sun, D.; Wei, N. MiR-155 inhibits transformation of macrophages into foam cells via regulating CEH expression. Biomed. Pharmacother. 2018, 104, 645-651. [CrossRef]

133. Li, X.; Kong, D.; Chen, H.; Liu, S.; Hu, H.; Wu, T.; Wang, J.; Chen, W.; Ning, Y.; Li, Y. miR-155 acts as an anti-inflammatory factor in atherosclerosis-associated foam cell formation by repressing calcium-regulated heat stable protein 1. Sci. Rep. 2016, 6, 21789. [CrossRef] [PubMed]

134. Dai, Y.; Wu, X.; Dai, D.; Li, J.; Mehta, J.L. MicroRNA-98 regulates foam cell formation and lipid accumulation through repression of LOX-1. Redox Biol. 2018, 16, 255-262. [CrossRef] [PubMed]

135. Wang, J.; Bai, X.; Song, Q.; Fan, F.; Hu, Z.; Cheng, G.; Zhang, Y. miR-223 inhibits lipid deposition and inflammation by suppressing toll-like receptor 4 signaling in macrophages. Int. J. Mol. Sci. 2015, 16, 24965-24982. [CrossRef] [PubMed]

136. Qiao, Y.; Wang, C.; Kou, J.; Han, D.; Huo, D.; Li, F.; Zhou, X.; Meng, D.; Xu, J.; Murtaza, G. MicroRNA-23a suppresses the apoptosis of inflammatory macrophages and foam cells in atherogenesis by targeting HSP90. Gene 2020, 729, 144319. [CrossRef] [PubMed]

137. Lin, N.; An, Y. Blockade of 146b-5p promotes inflammation in atherosclerosis-associated foam cell formation by targeting TRAF6. Exp. Ther. Med. 2017, 14, 5087-5092. [CrossRef]

138. Zhuang, X.; Li, R.; Maimaitijiang, A.; Liu, R.; Yan, F.; Hu, H.; Gao, X.; Shi, H. miR-221-3p inhibits oxidized low-density lipoprotein induced oxidative stress and apoptosis via targeting a disintegrin and metalloprotease-22. J. Cell. Biochem. 2019, 120, 6304-6314. [CrossRef]

139. Liang, X.; Xu, Z.; Yuan, M.; Zhang, Y.; Zhao, B.; Wang, J.; Zhang, A.; Li, G. MicroRNA-16 suppresses the activation of inflammatory macrophages in atherosclerosis by targeting PDCD4. Int. J. Mol. Med. 2016, 37, 967-975. [CrossRef]

140. Zhao, Q.; Li, S.; Li, N.; Yang, X.; Ma, S.; Yang, A.; Zhang, H.; Yang, S.; Mao, C.; Xu, L. miR-34a targets HDAC1-regulated H3K9 acetylation on lipid accumulation induced by homocysteine in foam cells. J. Cell. Biochem. 2017, 118, 4617-4627. [CrossRef] 
141. Wang, Y.-S.; Hsi, E.; Cheng, H.-Y.; Hsu, S.-H.; Liao, Y.-C.; Juo, S.-H.H. Let-7g suppresses both canonical and non-canonical NF-kB pathways in macrophages leading to anti-atherosclerosis. Oncotarget 2017, 8, 101026. [CrossRef]

142. Li, H.; Han, S.; Sun, Q.; Yao, Y.; Li, S.; Yuan, C.; Zhang, B.; Jing, B.; Wu, J.; Song, Y. Long non-coding RNA CDKN2B-AS1 reduces inflammatory response and promotes cholesterol efflux in atherosclerosis by inhibiting ADAM10 expression. Aging (Albany N. Y.) 2019, 11, 1695. [CrossRef]

143. Li, Y.; Sun, T.; Shen, S.; Wang, L.; Yan, J. LncRNA DYNLRB2-2 inhibits THP-1 macrophage foam cell formation by enhancing autophagy. Biol. Chem. 2019, 400, 1047-1057. [CrossRef] [PubMed]

144. Oram, J.F.; Vaughan, A.M. ABCA1-mediated transport of cellular cholesterol and phospholipids to HDL apolipoproteins. Curr. Opin. Lipidol. 2000, 11, 253-260. [CrossRef] [PubMed]

145. Attie, A.D. ABCA1: At the nexus of cholesterol, HDL and atherosclerosis. Trends Biochem. Sci. 2007, 32, 172-179. [CrossRef] [PubMed]

146. Su, Y.R.; Dove, D.E.; Major, A.S.; Hasty, A.H.; Boone, B.; Linton, M.F.; Fazio, S. Reduced ABCA1-mediated cholesterol efflux and accelerated atherosclerosis in Apolipoprotein E-deficient mice lacking macrophage-derived ACAT1. Circulation 2005, 111, 2373-2381. [CrossRef]

147. Ragozin, S.; Niemeier, A.; Laatsch, A.; Loeffler, B.; Merkel, M.; Beisiegel, U.; Heeren, J. Knockdown of hepatic ABCA1 by RNA interference decreases plasma HDL cholesterol levels and influences postprandial lipemia in mice. Arterioscler. Thromb. Vasc. Biol. 2005, 25, 1433-1438. [CrossRef]

148. Liu, Y.; Tang, C. Regulation of ABCA1 functions by signaling pathways. Biochim. Biophys. Acta BBA Mol. Cell Biol. Lipids 2012, 1821, 522-529. [CrossRef]

149. Yin, K.; Liao, D.-F.; Tang, C.-K. ATP-binding membrane cassette transporter A1 (ABCA1): A possible link between inflammation and reverse cholesterol transport. Mol. Med. 2010, 16, 438-449. [CrossRef]

150. Yvan-Charvet, L.; Ranalletta, M.; Wang, N.; Han, S.; Terasaka, N.; Li, R.; Welch, C.; Tall, A.R. Combined deficiency of ABCA1 and ABCG1 promotes foam cell accumulation and accelerates atherosclerosis in mice. J. Clin. Investig. 2007, 117, 3900-3908. [CrossRef]

151. Goedeke, L.; Vales-Lara, F.M.; Fenstermaker, M.; Cirera-Salinas, D.; Chamorro-Jorganes, A.; Ramírez, C.M.; Mattison, J.A.; de Cabo, R.; Suárez, Y.; Fernández-Hernando, C. A regulatory role for microRNA 33* in controlling lipid metabolism gene expression. Mol. Cell. Biol. 2013, 33, 2339-2352. [CrossRef] [PubMed]

152. Rayner, K.J.; Sheedy, F.J.; Esau, C.C.; Hussain, F.N.; Temel, R.E.; Parathath, S.; van Gils, J.M.; Rayner, A.J.; Chang, A.N.; Suarez, Y.; et al. Antagonism of miR-33 in mice promotes reverse cholesterol transport and regression of atherosclerosis. J. Clin. Investig. 2011, 121, 2921-2931. [CrossRef] [PubMed]

153. Baba, O. MicroRNA-33 Deficiency Reduces the Progression of Atherosclerotic Plaque in ApoE ${ }^{-/-}$Mice. Ph.D. Thesis, Kyoto University, Kyoto, Japan, 2014.

154. Zadelaar, S.; Kleemann, R.; Verschuren, L.; de Vries-Van der Weij, J.; van der Hoorn, J.; Princen, H.M.; Kooistra, T. Mouse models for atherosclerosis and pharmaceutical modifiers. Arter. Thromb. Vasc. Biol. 2007, 27, 1706-1721. [CrossRef]

155. Price, N.L.; Rotllan, N.; Canfrán-Duque, A.; Zhang, X.; Pati, P.; Arias, N.; Moen, J.; Mayr, M.; Ford, D.A.; Baldán, Á.; et al. Genetic dissection of the impact of miR-33a and miR-33b during the progression of atherosclerosis. Cell Rep. 2017, 21, 1317-1330. [CrossRef]

156. Price, N.L.; Singh, A.K.; Rotllan, N.; Goedeke, L.; Wing, A.; Canfran-Duque, A.; Diaz-Ruiz, A.; Araldi, E.; Baldan, A.; Camporez, J.P.; et al. Genetic Ablation of miR-33 Increases Food Intake, Enhances Adipose Tissue Expansion, and Promotes Obesity and Insulin Resistance. Cell Rep. 2018, 22, 2133-2145. [CrossRef]

157. Chen, W.-J.; Yin, K.; Zhao, G.-J.; Fu, Y.-C.; Tang, C.-K. The magic and mystery of microRNA-27 in atherosclerosis. Atherosclerosis 2012, 222, 314-323. [CrossRef]

158. Vickers, K.C.; Shoucri, B.M.; Levin, M.G.; Wu, H.; Pearson, D.S.; Osei-Hwedieh, D.; Collins, F.S.; Remaley, A.T.; Sethupathy, P. MicroRNA-27b is a regulatory hub in lipid metabolism and is altered in dyslipidemia. Hepatology 2013, 57, 533-542. [CrossRef] [PubMed]

159. Shirasaki, T.; Honda, M.; Shimakami, T.; Horii, R.; Yamashita, T.; Sakai, Y.; Sakai, A.; Okada, H.; Watanabe, R.; Murakami, S. MicroRNA-27a regulates lipid metabolism and inhibits hepatitis $\mathrm{C}$ virus replication in human hepatoma cells. J. Virol. 2013, 87, 5270-5286. [CrossRef] [PubMed]

160. Cheung, S.H.; Kwok, W.K.; To, K.F.; Lau, J.Y.W. Anti-atherogenic effect of hydrogen sulfide by over-expression of cystathionine gamma-lyase (CSE) gene. PLoS ONE 2014, 9, e113038. [CrossRef]

161. Greco, S.; Fasanaro, P.; Castelvecchio, S.; D’Alessandra, Y.; Arcelli, D.; Di Donato, M.; Malavazos, A.; Capogrossi, M.C.; Menicanti, L.; Martelli, F. MicroRNA dysregulation in diabetic ischemic heart failure patients. Diabetes 2012, 61, $1633-1641$. [CrossRef]

162. Mani, S.; Li, H.; Untereiner, A.; Wu, L.; Yang, G.; Austin, R.C.; Dickhout, J.G.; Lhoták, Š.; Meng, Q.H.; Wang, R. Decreased endogenous production of hydrogen sulfide accelerates atherosclerosis. Circulation 2013, 127, 2523-2534. [CrossRef]

163. Peh, M.T.; Anwar, A.B.; Ng, D.S.; Atan, M.S.B.M.; Kumar, S.D.; Moore, P.K. Effect of feeding a high fat diet on hydrogen sulfide (H2S) metabolism in the mouse. Nitric Oxide 2014, 41, 138-145. [CrossRef]

164. Guo, Z.; Li, C.S.; Wang, C.M.; Xie, Y.J.; Wang, A.L. CSE/H2S system protects mesenchymal stem cells from hypoxia and serum deprivation-induced apoptosis via mitochondrial injury, endoplasmic reticulum stress and PI3K/Akt activation pathways. Mol. Med. Rep. 2015, 12, 2128-2134. [CrossRef] [PubMed] 
165. Waki, H.; Nakamura, M.; Yamauchi, T.; Wakabayashi, K.-I.; Yu, J.; Hirose-Yotsuya, L.; Take, K.; Sun, W.; Iwabu, M.; Okada-Iwabu, M. Global mapping of cell type-specific open chromatin by FAIRE-seq reveals the regulatory role of the NFI family in adipocyte differentiation. PLoS Genet. 2011, 7, e1002311. [CrossRef] [PubMed]

166. Chen, L.-J.; Lim, S.H.; Yeh, Y.-T.; Lien, S.-C.; Chiu, J.-J. Roles of microRNAs in atherosclerosis and restenosis. J. Biomed. Sci. 2012, 19, 79. [CrossRef]

167. Nazari-Jahantigh, M.; Wei, Y.; Noels, H.; Akhtar, S.; Zhou, Z.; Koenen, R.R.; Heyll, K.; Gremse, F.; Kiessling, F.; Grommes, J. MicroRNA-155 promotes atherosclerosis by repressing Bcl6 in macrophages. J. Clin. Investig. 2012, 122, 4190-4202. [CrossRef] [PubMed]

168. Rodriguez, A.; Vigorito, E.; Clare, S.; Warren, M.V.; Couttet, P.; Soond, D.R.; Van Dongen, S.; Grocock, R.J.; Das, P.P.; Miska, E.A. Requirement of bic/microRNA-155 for normal immune function. Science 2007, 316, 608-611. [CrossRef] [PubMed]

169. Celermajer, D.S.; Chow, C.K.; Marijon, E.; Anstey, N.M.; Woo, K.S. Cardiovascular disease in the developing world: Prevalences, patterns, and the potential of early disease detection. J. Am. Coll. Cardiol. 2012, 60, 1207-1216. [CrossRef] [PubMed] 